Hippocampus - Research Article - HIPO-16-192R

\title{
Relaxin-3 Inputs Target Hippocampal Interneurons and Deletion of Hilar Relaxin-3 \\ Receptors in 'Floxed-RXFP3' Mice Impairs Spatial Memory
}

$\underline{\text { Haidar }}^{1,2}$, Guèvremont $\mathrm{G}^{3}$, Zhang $\mathrm{C}^{1,2}$, Bathgate $\operatorname{RAD}^{1,2,4}$, Timofeeva $\mathrm{E}^{3}$, Smith $\mathrm{CM}^{1,2,5 *}$, Gundlach $\mathrm{AL}^{1,2,6 *}$

${ }^{1}$ The Florey Institute of Neuroscience and Mental Health, Parkville, Victoria, Australia

${ }^{2}$ Florey Department of Neuroscience and Mental Health, The University of Melbourne, Victoria, Australia

${ }^{3}$ Department of Psychiatry and Neurosciences, Faculty of Medicine, Laval University, Quebec, Canada

${ }^{4}$ Department of Biochemistry and Molecular Biology, The University of Melbourne, Victoria, Australia

${ }^{5}$ School of Medicine, Deakin University, Victoria, Australia

${ }^{6}$ Department of Anatomy and Neuroscience, The University of Melbourne, Victoria, Australia

* These authors jointly supervised this research

Correspondence

Pr Andrew L. Gundlach

The Florey Institute of Neuroscience and Mental Health

30 Royal Parade, Parkville, Victoria 3052, Australia

andrew.gundlach@florey.edu.au

Phone: +61 390356507 Fax: +61 390350321

Running title: Deletion of hilar relaxin-3 receptors impairs spatial memory

Number of text pages: 19

Number of Figures: 9 and 2 supplementary figures

Number of Tables: 3

Key words: Cre/LoxP; dentate gyrus; GABA/somatostatin interneurons; nucleus incertus; RXFP3

Grant Sponsor: National Health and Medical Research Council of Australia; Grant number: 1024885

(ALG) and 1067522 (ALG, RADB); Grant Sponsor: Brain \& Behavior Research Foundation (USA) NARSAD Independent Investigator Award (ALG); Grant Sponsor: Victorian Government Operational Infrastructure Support Programme (FINMH). Grant Sponsor: Natural Sciences and Engineering Research Council of Canada (ET); Grant Sponsor: Canadian Institutes of Health Research (ET); Grant Sponsor: Alzheimer's Australia Dementia Research Foundation, Postgraduate Scholarship (MH).

Grant Sponsor: Bethlehem Griffiths Research Foundation, Postgraduate Scholarship (CZ).

This is the author manuscript accepted for publication and has undergone full peer review but has not been through the copyediting, typesetting, pagination and proofreading process, which may lead to differences between this version and the Version record. Please cite this article as doi:10.1002/ hipo.22709. 


\section{ABSTRACT}

Hippocampus is innervated by $\gamma$-aminobutyric acid (GABA) 'projection' neurons of the nucleus incertus (NI), including a population expressing the neuropeptide, relaxin-3 (RLN3). In studies aimed at gaining an understanding of the role of RLN3 signaling in hippocampus via its $\mathrm{G}_{\mathrm{i} / \mathrm{o}}$-protein-coupled receptor, RXFP3, we examined the distribution of RLN3-immunoreactive nerve fibres and RXFP3 mRNA-positive neurons in relation to hippocampal GABA neuron populations. RLN3-positive elements were detected in close-apposition with a substantial population of somatostatin (SST)- and GABA-immunoreactive neurons, and a smaller population of parvalbumin- and calretininimmunoreactive neurons in different hippocampal areas, consistent with the relative distribution patterns of RXFP3 mRNA and these marker transcripts. In light of the functional importance of the dentate gyrus (DG) hilus in learning and memory, and our anatomical data, we examined the possible influence of RLN3/RXFP3 signaling in this region on spatial memory. Using viral-based Cre/LoxP recombination methods and adult mice with a 'floxed' Rxfp3 gene, we deleted Rxfp3 from DG hilar neurons and assessed spatial memory performance and affective behaviors. Following infusions of an $\mathrm{AAV}^{(1 / 2)}$-Cre-IRES-eGFP vector, Cre expression was observed in DG hilar neurons, including SSTpositive cells, and in situ hybridization histochemistry for RXFP3 mRNA confirmed receptor deletion relative to levels in floxed-RXFP3 mice infused with an AAV ${ }^{(1 / 2)}$-eGFP (control) vector. RXFP3 depletion within the DG hilus impaired spatial reference memory in an appetitive T-maze task reflected by a reduced percentage of correct choices and increased time to meet criteria, relative to control. In a continuous spontaneous alternation Y-maze task, RXFP3-depleted mice made fewer alternations in the first minute, suggesting impairment of spatial working memory. However, RXFP3depleted and control mice displayed similar locomotor activity, anxiety-like behavior in light/dark box and elevated-plus maze tests, and learning and long-term memory retention in the Morris water maze. These data indicate endogenous RLN3/RXFP3 signaling can modulate hippocampal-dependent spatial reference and working memory via effects on SST interneurons, and further our knowledge of hippocampal cognitive processing.

John Wiléy \& Sons

This article is protected by copyright. All rights reserved. 


\section{INTRODUCTION}

The hippocampus plays an important role in learning and memory, in both rodents and humans (O'Keefe and Nadel, 1978; Burgess et al., 2002). The hilus (or hilar region) of the dentate gyrus (DG) contains a diverse population of interneurons, which are thought to be crucial in mediating these roles (Freund and Buzsaki, 1996). Interneurons within the DG hilus (as well as hippocampal CA1 and CA3 fields) receive GABAergic and cholinergic inputs from the medial septum/diagonal band of Broca (MS/DB) (Freund and Antal, 1988; Dutar et al., 1995; Vertes and Kocsis, 1997), which together with a number of other subcortical structures (e.g. supramammillary nucleus (Kocsis and Vertes, 1997; Ruediger et al., 2011), median raphe (MR) (Vertes et al., 1999; McKay et al., 2013) constitute the 'septohippocampal system' (Freund and Antal, 1988; Dutar et al., 1995; Vertes and Kocsis, 1997). The majority of GABAergic septal projection neurons terminate on DG hilus interneurons (Freund and Antal, 1988; Amaral et al., 2007) participating in the control of hippocampal theta oscillations (Vertes and Kocsis, 1997; Vertes, 2005; Lubenov and Siapas, 2009), and the processing of cognitive and spatial maps (O'Keefe, 1993; Leutgeb et al., 2005; Schiller et al., 2015).

In addition to these well characterized forebrain subcortical sources of afferent input, brainstem GABA projections to the hippocampus have been characterized (see Brown and McKenna, 2015, for review). GABAergic projections from the nucleus incertus (NI) (Nunez et al., 2006; Olucha-Bordonau et al., 2012; Ma et al., 2013; Sanchez-Perez et al., 2015) and nucleus of Gudden (VTg) (Bassant and Poindessous-Jazat, 2001; Kocsis et al., 2001; Bassant and Poindessous-Jazat, 2002) can regulate hippocampal theta rhythm (4-8 Hz in rodents and 4-12 Hz in humans), which is important for spatial navigation and memory formation. The NI, which sits within the dorsal tegmentum, sends strong GABA-positive projections to the MS/DB, hippocampus, supramammillary nucleus and MR nucleus, amongst other hypothalamic and limbic circuits that influence hippocampal activity (Goto et al., 2001; Olucha-Bordonau et al., 2003). Stimulation of the NI in urethane-anesthetized rats increased theta and decreased delta rhythm activity in the hippocampus, whereas electrolytic lesions of the NI abolished hippocampal theta rhythm (Nunez et al., 2006).

More recently, it was reported that lidocaine infusion into the NI impaired long-term spatial memory of adult rats in a Morris water maze (MWM) (Nategh et al., 2015) and delayed learning and impaired retention in a passive avoidance learning (PAL) task (Nategh et al., 2016), which are both hippocampal-dependent memory tasks. In the latter study, perforant path-DG short-term synaptic plasticity was also examined upon NI inactivation, both before a paired-pulse stimulation, and before or after tetanic stimulation, in freely-moving rats; revealing that NI inactivation did not change the perforant path-DG granule cell synaptic input, but decreased the excitability of DG granule cells, consistent with an effect of normal NI activity to inhibit the inhibitory interneurons in the DG and disinhibit granule cells (Nategh et al., 2016). 
A large population of NI neurons express abundant levels of the neuropeptide relaxin-3 (RLN3) (Bathgate et al., 2002; Burazin et al., 2002), which acts via its cognate $\mathrm{G}_{\mathrm{i} / \mathrm{o}}$-protein coupled receptor, relaxin family peptide 3 receptor (RXFP3) (Liu et al., 2003; Bathgate et al., 2006). RLN3 neurons in the NI co-express glutamate decarboxylase (GAD), the enzyme involved in converting glutamate to GABA) (Ma et al., 2007). RLN3-positive efferents overlap extensively with NI forebrain projections (Ma et al., 2007; Ma et al., 2009c; Smith et al., 2010), and in a GAD2-Cre reporter mouse, injection of a Cre-dependent viral vector expressing enhanced yellow fluorescent protein (eYFP) into the NI produced strong eYFP colocalization with RLN3-IR in NI neurons, and in hippocampus (including DG hilus) extensive eYFP-IR was observed, suggesting RLN3- and GAD-positive neurons in the NI provide projections to the hippocampus (S Ma, personal communication). RLN3-positive fibres make close contacts with MS/DB neurons which project to the hippocampus, including populations that express choline acetyltransferase (ChAT) or GAD67 and/or parvalbumin (PV) cells (Olucha-Bordonau et al., 2012), which are known to act as 'pacemaker' cells for hippocampal theta rhythm. Furthermore, the distribution of RLN3 fibres strongly overlaps with that of RXFP3 mRNA in the MS/DB and hippocampus, and other forebrain areas (Tanaka et al., 2005; Ma et al., 2007; Smith et al., 2010). Injection of a RXFP3-selective agonist peptide (R3/I5; Liu et al., 2005) into the MS increased hippocampal theta rhythm in urethane-anesthetized rats, which was significantly attenuated by prior injection of a selective RXFP3 antagonist (R3(B $\Delta 23-27) R / I 5$, Kuei et al., 2007). In conscious rats, R3/I5 injection into the MS increased hippocampal theta rhythm in a home cage environment, whereas injections of $\mathrm{R} 3(\mathrm{~B} \Delta 23-27) \mathrm{R} / \mathrm{I} 5$ dose-dependently reduced hippocampal theta rhythm in rats exploring a novel, enriched context, and impaired performance in a spontaneous alternation task (SAT) (Ma et al., 2009a). However, the neurochemical mechanism(s) by which the RLN3/RXFP3 system modulates hippocampal activity are largely unknown and there are no studies of this system in mice.

In the present studies designed to address this gap in knowledge, the first aim was to determine which hippocampal neurons are potentially regulated by RLN3/RXFP3 signaling. We initially examined the regional distribution of RXFP3 mRNA in the mouse hippocampus, but due to the current unavailability of a fully validated RXFP3 antibody, double-label immunohistochemistry studies to neurochemically phenotype RXFP3-positive neurons were not possible. Therefore, we conducted a series of double- and triple-label immunohistochemical experiments using a characterized monoclonal RLN3 antisera and antisera raised against key markers expressed by the hippocampus, including GABA, the neuropeptide somatostatin (SST), and the calcium-binding proteins PV and calretinin (CR). Next we assessed the behavioral role of the RLN3/RXFP3 system within the DG hilus in 'floxed-RXFP3' mice, in which the endogenous RXFP3 gene is flanked by two loxP sites ('floxed'). In these floxed-RXFP3 mice, RXFP3 can be 'conditionally' deleted from neurons within discrete brain regions of adult mice by local viral delivery of the Cre recombinase restriction enzyme, which detects 
loxP sites and deletes the stretch of DNA between them (Ryding et al., 2001). Thus, this approach provides temporal control and spatial specificity of receptor deletion.

These studies have revealed that RLN3-positive fibres terminate on a population of SST- and GABA-positive neurons, and a smaller population of PV-and CR-positive neurons. Appositions were observed most notably with SST-positive neurons in the DG hilus, as well as in CA1 and CA3 fields. Interestingly, conditional hippocampal RXFP3 depletion in the DG hilus impaired spatial reference memory in mice, in an appetitive T-maze reference memory task and spatial working memory in a continuous SAT in a Y-maze. We also assessed anxiety-like behavior, based on the key functional influence of the ventral hippocampus on stress and anxiety (Bannerman et al., 2004; Engelmann et al., 2006), and on the substantial number of neuroanatomical and functional studies that suggest a role for RLN3/RXFP3 signaling in responses to stress and anxiety (Banerjee et al., 2010; Smith et al., 2011; Watanabe et al., 2011; Shabanpoor et al., 2012; Ma et al., 2013; Ryan et al., 2013; Smith et al., 2014). Notably however, anxiety-like behavior was unaltered, suggesting a likely regional functional specificity of RLN3/RXFP3 signaling within the hippocampus, although the viral spread did not extend across the entire dorsoventral extent of the DG hilus in the ventral hippocampus, therefore likely reducing any potential effect on anxiety-like behavior. Taken together, these findings suggest that endogenous RLN3/RXFP3 signaling modulates neurons within the DG hilus, particularly a population of GABA/SST-expressing neurons, to promote spatial reference and working memory (Andrews-Zwilling et al., 2012).

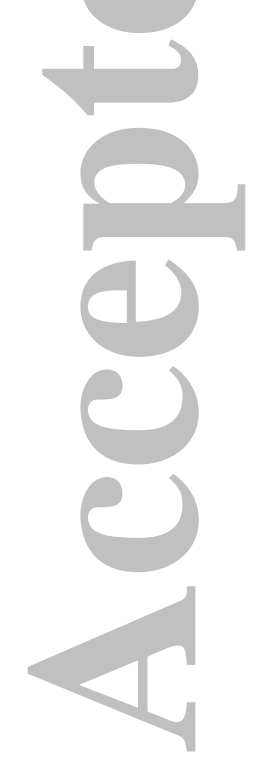




\section{MATERIALS AND METHODS}

Mice

'Floxed-RXFP3' mice were generated by Gen-O-way (Paris, France), and kindly supplied by Janssen Pharmaceutical Companies of Johnson \& Johnson (La Jolla, CA, USA), and bred within The Florey Institute of Neuroscience and Mental Health Animal Facility. These mice possess a 5'-loxP site located $1.4 \mathrm{~kb}$ upstream of the RXFP3 5'UTR, while a 3'-loxP site is located directly after the STOP codon and upstream of the 3 'UTR. Floxed-RXFP3 mice were originally generated on a 129SV/B6 mixed background before being subjected to successive rounds of backcrossing onto a C57BL/6 background for 8-10 generations, via a $>99 \%$ purity speed congenic approach. All studies were conducted with approval from The Florey Institute of Neuroscience and Mental Health Animal Ethics Committee and were in accordance with ethical guidelines issued by the National Health and Medical Research Council of Australia.

Behavioral experiments were performed on male homozygous RXFP3-floxed mice between 1120 weeks of age ( $n=12-13$ per group). Mice were group housed (mixed treatments, $\sim 4$ mice per box) for the duration of studies. Mice were acclimatized to behavioral rooms $24 \mathrm{~h}$ prior to testing, and were maintained on a 12-h light-dark cycle (lights on 0700-1900) with regular chow and water available ad libitum, except during a food restriction regime used during T-maze testing (see below).

\section{Detection of RXFP3 mRNA by In Situ Hybridization Histochemistry}

Mice were deeply anesthetized with 5\% isoflurane inhalation (Delvet, Seven Hills, NSW, Australia) and then administered sodium pentobarbital $(100 \mathrm{mg} / \mathrm{kg} .0 .1 \mathrm{ml}$, i.p.) and transcardially perfused with $0.1 \mathrm{M}$ phosphate buffer (PB, $2.7 \mathrm{mM} \mathrm{KCI}, 11.2 \mathrm{mM} \mathrm{Na}_{2} \mathrm{HPO}_{4}, 1.8 \mathrm{mM} \mathrm{KH}_{2} \mathrm{PO}_{4}$, pH 7.4) followed by $4 \%$ paraformaldehyde (PFA) in $0.1 \mathrm{M} \mathrm{PB}$. Mice were decapitated and their brains removed and post-fixed in 4\% PFA in $0.1 \mathrm{M}$ PB for 6 days. Brains were then transferred to a solution of $4 \%$ PFA and $20 \%$ sucrose in $0.1 \mathrm{M} \mathrm{PB}$ and kept at $4{ }^{\circ} \mathrm{C}$ overnight. Brains were frozen on dry ice and $25 \mu \mathrm{m}$ sections were cut using a sliding microtome (Histoslide 2000, Heidelberg, Germany). Levels of RXFP3 mRNA expression in the hippocampus were analyzed by in situ hybridization as described (Martin and Timofeeva, 2010; Lenglos et al., 2014; Lenglos et al., 2015). An RXFP3 riboprobe was generated from the 907-bp fragment of rat RLN3 receptor RXFP3 cDNA (Gene bank NM_001008310; the probe included 274-1180 bp sequence of the complete 1431 bp rat RXFP3 cDNA; forward primer: 5'-AGCGCC-GTTTACTGGGTGGTTTG-3'; reverse primer: 5'TGGGGTTGAGGCAGCTGTTGGAGT-3'). NCBI BLAST sequencing revealed that the cDNA for rat RXFP3 is $93 \%$ homologous to mouse RXFP3.

\section{Double- and Triple-Label Immunohistochemistry for RLN3 and GABA, CR, PV or SST}

For analysis of RLN3 in nerve fibres in relation to key neurochemical markers of hippocampal neurons, a sequential double- and triple-label immunohistochemistry protocol was used. To enhance 
immunoreactivity in cell bodies, 10 week-old male mice $(n=3)$ were administered colchicine $(20 \mu \mathrm{g}$ in $5 \mu \mathrm{l}$ ) into the lateral ventricle using a stereotaxic procedure (described below), at a rate of $1 \mu \mathrm{l}$ per min. Sixteen (16) h post-surgery, mice were transcardially perfused (4\% PFA in $0.1 \mathrm{M} \mathrm{PB})$ and postfixed in 4\% PFA in $0.1 \mathrm{M} \mathrm{PB}$ for $1 \mathrm{~h}$ at RT, then transferred to a solution of $20 \%$ sucrose in $0.1 \mathrm{M} \mathrm{PB}$ and kept at $4^{\circ} \mathrm{C}$ overnight. Brains were then embedded in O.C.T. (Tissue-Tek; Sakura Finetek, USA) and frozen over dry ice and stored at $-80^{\circ} \mathrm{C}$. Forty $(40) \mu \mathrm{m}$ coronal sections were cut and collected into 4 series spanning from $-1.22 \mathrm{~mm}$ to $-3.80 \mathrm{~mm}$ from Bregma using a cryostat (Cryocut 1800, Leica Microsystems, Heerbrugg, Switzerland) at $-18^{\circ} \mathrm{C}$ and stored in cryoprotectant solution (30\% ethylene glycol, $30 \%$ glycerol, $0.05 \mathrm{M} \mathrm{PB})$ at $-20^{\circ} \mathrm{C}$.

All sections were washed $3 \times 5$ min with $0.1 \%$ Triton X-100 in $0.1 \mathrm{M} \mathrm{PB}$, and then blocked in $10 \%$ normal horse serum (NHS) in $0.1 \%$ Triton X-100, $0.1 \mathrm{M}$ PB for $1 \mathrm{~h}$ at RT. Sections were incubated with a mouse monoclonal RLN3 antibody (HK4-144-10; Kizawa et al., 2003; Tanaka et al., 2005; Ma et al., 2013) in 2\% NHS and $0.1 \%$ Triton X-100 in 0.1M PB overnight at RT (for dilutions and information about the primary antisera used, see Table S1). On the following day, sections were washed $3 \times 5 \mathrm{~min}$ in $0.1 \mathrm{M} \mathrm{PB}$, followed by incubation in donkey anti-mouse Alexa-594 (JIR, 715585151, 1:500) or donkey anti-mouse Alexa-647 (JIR, 715605151, 1:500) in 0.1 M PB for $1 \mathrm{~h}$ at RT. Following application of the secondary antibody for visualization of RLN3-IR, sections were washed $3 \times 5$ min with $0.1 \mathrm{M}$ PB and incubated with either: (1) rabbit anti-GABA (Sigma, A2052, 1:3,000) (2) rabbit anti-PV (Abcam, ab11427, 1:1,000) and rat anti-SST (Millipore, MAB354, 1:200) (3) and rabbit anti-CR (Swant, CR7697, 1:1,000) in 2\% NHS, 0.1\% Triton X-100, 0.1 M PB overnight at RT. Sections were washed $3 \times 5 \mathrm{~min}$ in $0.1 \mathrm{M}$ PB before incubation in the following secondary antibodies (1) donkey anti-rabbit Alexa-488 (Life Tech, A21206, 1:500) (2) donkey anti-rat Alexa-488 (Life Tech, A21208, 1:500) and donkey anti-rabbit Alexa-594 (JIR, 711585152, 1:500) and (3) donkey anti-rabbit Alexa-488 (Life Tech, A21206, 1:500) in 0.1 M PB for $1 \mathrm{~h}$ at RT. Following the secondary antisera incubation, sections were washed $3 \times 5$ min with $0.1 \mathrm{M}$ PB and mounted on glass slides using Fluoromount-G (Southern Biotech, Birmingham, AL, USA).

Resultant staining was observed under a LSM 780 Zeiss Axio Imager 2 confocal laser scanning microscope (Carl Zeiss AG, Jena, Germany). Each fluorescence channel was imaged sequentially using a $20 \times$ objective for mosaic $\mathrm{z}$ stacks ( $1 \mu \mathrm{m}$ intervals $)$ and the total proportions of GABA-, SST-, PV- and CR- positive neurons contacted by RLN3-IR fibres were manually counted from the dorsal hippocampus of a representative unilateral coronal section from 3 mice $(-2.54 \mathrm{~mm}$ from Bregma) based on the strong RLN3 fibre innervation observed at this coronal level. Mosaic z-stack images covering the entire hippocampus from each representative coronal section were obtained with $10 \%$ overlap between each image on the X-Y plane, and a defined region was set up for the z plane to scan from the bottom to the top of each image comprising the mosaic. Z-stack images $(63 \times$ objective, 0.1 $\mu \mathrm{m}$ intervals) were taken to further evaluate putative contacts between RLN3-IR nerve fibres and 
hippocampal cellular markers. A putative contact was scored when an RLN3-IR fibre/terminal bouton was observed immediately adjacent to the cell body of a neuron expressing a hippocampal marker.

\section{Adeno-Associated Viral (AAV) Vectors}

The AAV mosaic serotype 1/2 with capsid from AAV1 and ITR (internal terminal repeats) AAV2 was purified and harvested as described (Ganella et al., 2013). The AAV ${ }^{(1 / 2)-}$ Cre-IRES-eGFP viral vector encodes Cre recombinase and an enhanced green fluorescent protein marker (eGFP) linked by an IRES sequence (internal ribosome entry site), allowing for the expression of Cre recombinase and eGFP from a single vector. The control $\mathrm{AAV}^{(1 / 2)-}$ eGFP construct was also packaged in a $1 / 2$ mosaic capsid, encoding the expression of eGFP marker protein. Transcription of both constructs was driven by the chicken $\beta$-actin (sCAG) promoter. The titres were assessed visually in HEK293T cells under a fluorescent microscope and by measuring genomic copies (gc) per $\mathrm{ml}(\mathrm{gc} / \mathrm{ml})$, using quantitative polymerase chain reaction (qPCR). The resulting titre of $\mathrm{AAV}^{(1 / 2)-} \mathrm{Cre}-\mathrm{IRES}-\mathrm{eGFP}$ and the control $\mathrm{AAV}^{(1 / 2)}$-eGFP vector were approximately $2 \times 10^{11} \mathrm{gc} / \mathrm{ml}$.

\section{Stereotaxic Surgery}

Mice were initially anesthetized with 5\% isoflurane inhalation (Delvet) mixed with oxygen till loss of righting reflex, then secured in a small animal stereotaxic frame (Kopf Instruments, Tujunga, CA, USA) with 1.5-2\% isoflurane delivered through a small animal nose cone. Analgesic (Meloxicam $20 \mathrm{mg} / \mathrm{kg}$; Troy Laboratories, Smithfield, NSW, Australia) was then administered intraperitoneally (i.p., $0.1 \mathrm{ml}$ ), and eyes were moistened with lubricating eye ointment (Lacri-Lube, Allergen, New Jersey, USA). A small midline incision was made to expose the skull, which was then cleaned/dried with $6 \%$ hydrogen peroxide. $A A V^{(1 / 2)}$-Cre-IRES-eGFP viral vector or control AAV ${ }^{(1 / 2)}$-eGFP viral vector was loaded into a glass capillary injector which was connected to polyethylene tubing and a 10 $\mu \mathrm{l}$ Hamilton syringe (0.46 mm diameter, Harvard Apparatus, Holliston, MA, USA), and mounted on an infusion pump (PicoPlus, Harvard). Small holes were drilled through the skull above the injection sites, and the glass capillary was lowered to the following coordinates from Bregma based on the mouse brain atlas (Paxinos and Franklin, 2001): anterior-posterior, -2.3 mm; medial-lateral, -1.60 mm; dorsal-ventral, $-2.1 \mathrm{~mm}$; adjusted proportionally for skull size, determined by bregma-interaural distance). Viral vectors were infused at a rate of $0.1 \mu \mathrm{l} / \mathrm{min}$ to a total volume of $1 \mu \mathrm{l}$. After each infusion, the injector was left in place for $7 \mathrm{~min}$, retracted $1.0 \mathrm{~mm}$, and left for another min to minimize deposition of virus in the injection tract, before being slowly removed. After surgery, the skin incision site and holes in the skull were closed/sealed with glue (superglue, Daiso, Hiroshima, Japan) and a single suture. After surgery mice were placed in recovery chambers $\left(30^{\circ} \mathrm{C}\right.$, Thermacage, Datesand Ltd., Manchester, UK) for $\sim 1 \mathrm{~h}$, and left to recover for 3 weeks to allow for Cre expression, RXFP3 gene deletion, and subsequent RXFP3 protein deletion. 


\section{Validation of Cre Expression (Cre-IR) Within SST-Positive Neurons}

In studies to assess Cre-recombinase expression in the targeted area and the expression of Cre within SST-positive neurons, coronal sections $(40 \mu \mathrm{m})$ were washed $3 \times 5$ min with $0.1 \%$ Triton X100 in $0.1 \mathrm{M} \mathrm{PB}$, and then blocked in $10 \%$ NHS in $0.1 \%$ Triton X-100 and $0.1 \mathrm{M} \mathrm{PB}$ for $1 \mathrm{~h}$ at RT. Tissue were then incubated with rabbit polyclonal Cre antibody (Novagen, 69050-3, 1:500, $n=3$ ) and rat monoclonal anti-SST (Millipore, MAB354, 1:200, $n=3$ ) in 2\% NHS and $0.1 \%$ Triton X-100 overnight at RT. On the following day, sections were washed $3 \times 5$ min in $0.1 \mathrm{M} \mathrm{PB}$, followed by incubation in anti-rabbit Alexa-594 secondary antibody (Jackson ImmunoResearch Laboratories, Address, USA, 120330, 1:500) and anti-rat Alexa-594 secondary antibody (1:500) in $0.1 \mathrm{M} \mathrm{PB}$. Sections were then washed $3 \times 5$ min with $0.1 \mathrm{M}$ PB and mounted on glass slides using FluoromountG (Southern Biotech, Birmingham, AL, USA). The resulting staining was observed under a Zeiss Axio Imager 2 confocal laser-scanning microscope (Carl Zeiss AG, Jena, Germany).

\section{Validation of RXFP3 mRNA Deletion}

RXFP3 mRNA loss following AAV ${ }^{(1 / 2)}$-Cre-IRES-eGFP injection, was measured in mice injected bilaterally with $\mathrm{AAV}^{(1 / 2)}$-Cre-IRES-eGFP $(n=5)$, or with $\mathrm{AAV}^{(1 / 2)}$-eGFP $(n=3)$. Twenty-one days after stereotaxic surgery, mice were transcardially perfused (4\% PFA in $0.1 \mathrm{MPB}$ ). For quantitative analyses, slides were examined with dark-field microscopy using an Olympus BX61 microscope (Olympus Canada, Richmond Hill, ON, Canada). Images were acquired with a DVC-2000C digital camera (Thorslabs Scientific Imaging, Austin, TX, USA) and analyzed with Stereo Investigator software (MBF Bioscience, Williston, VT, USA). Brain sections from bregma $-1.7 \mathrm{~mm}$ to $-2.7 \mathrm{~mm}$ (based on a stereotaxic atlas of mouse brain, (Paxinos and Franklin, 2001)) were used for quantitative analyses. The optical density (OD) was obtained by defining the contour of the region of interest (DG and CA3), and three background contours (regions without positive hybridization signal) were collected to correct for the average background signal. This analysis was taken from 3-5 sections on each side of the brain for bilaterally injected mice, and from 7-12 sections from unilaterally injected mice. The mean $\mathrm{OD}$ of $\mathrm{AAV}^{(1 / 2)}$-Cre injected tissue was normalized to the mean value of RXFP3 mRNA in $\mathrm{AAV}^{(1 / 2)}$-GFP injected tissue, to obtain the relative level of RXFP3 mRNA for each section.

\section{Validation of Cre Targeting of Dentate Gyrus Hilus}

Following confirmation that local hippocampal injection of $\mathrm{AAV}^{(1 / 2)}$-Cre-IRES-eGFP viral vector resulted in Cre expression and deletion of RXFP3 mRNA in floxed-RXFP3 mice, in subsequent studies, the presence of Cre-IR throughout the DG hilus was taken as sufficient evidence of adequate RXFP3 deletion within this structure. For all histological analyses a 1-in-3 series of brain sections was collected spanning from $-1.22 \mathrm{~mm}$ to $-3.80 \mathrm{~mm}$ from Bregma (Paxinos and Franklin, 2001), and only mice which had consistent expression of Cre-IR throughout the DG hilus of dorsal hippocampus were included in behavioral analyses. Of the 16 mice that received bilateral $\mathrm{AAV}^{(1 / 2)}{ }^{-}$Cre-IRES-eGFP 
injections, 4 mice were excluded from the analyses due to a lack of transduced neurons present in the DG hilus. No viral spread was observed outside the DG and CA3.

\section{Behavioral Tests}

All behavioral experiments were conducted during the light phase, between 0900-1700 h, and were conducted from 21 days after surgery in the following order: (1) Automated locomotor cell; (2) Morris water maze (MWM); (3) Light/dark box; (4) Elevated plus maze; (5) Continuous spontaneous alternation test, and; (6) Appetitive spatial reference T-maze test. All mice were sacrificed 3 days after behavioral testing for histological analyses.

\section{Automated Locomotor Cell}

Mice were tested in a $27 \times 27 \mathrm{~cm}$ automated locomotor cell (Med Associates, Fairfax, Vermont, USA), illuminated by 70 lux light, for a total duration of $1 \mathrm{~h}$. The total distance travelled was tracked by a photobeam array. Data was analyzed using Activity Monitor, v.9.02 software (v.6.02; Med Associates).

\section{Morris Water Maze (MWM)}

In a test of hippocampus-dependent spatial reference long-term memory, mice were trained in a circular pool (1.2 $\mathrm{m}$ diameter) to locate a hidden platform $(10 \mathrm{~cm}$ diameter) which was submerged $\sim 0.5-1 \mathrm{~cm}$ beneath opaque water, made using non-toxic white paint and maintained at $18-22^{\circ} \mathrm{C}$. The pool was surrounded by distal extra-maze cues. The acquisition phase consisted of 6 consecutive training days with 4 trials per day, with an inter-trial interval (ITI) of $30 \mathrm{~min}$. For each trial, mice were placed in from a semi-random starting location (N, NW, E, SE) facing the pool wall, and were allowed to swim until they found the hidden platform or for a maximum of $30 \mathrm{~s}$. If a mouse failed to locate the platform within the allocated time, the experimenter guided the mouse to the platform. The mouse then remained on the platform for $30 \mathrm{~s}$, before being returned to its home cage, and allowed to dry under a heat lamp. For the acquisition sessions, a mean latency to locate the target quadrant was calculated for each mouse by averaging the latency to reach the platform across all 4 trials. Twentyfour (24) $\mathrm{h}$ after the last training day, the platform was removed from the target quadrant and the mice were allowed to swim freely for a duration of $120 \mathrm{~s}$. The percent time spent in the target quadrant and the number of platform crossings was calculated.

\section{Anxiety-like Behavior - Light/Dark Box}

Mice were placed in the automated cells described above with half of the locomotor cell fitted with a black Perspex box, which was impermeable to visible light. The other half was exposed to a light-emitting diode array, illuminated the light side to 700 lux in the centre and 650 lux in the corners, creating an aversive environment. For testing, mice were placed in the dark side of the apparatus for $10 \mathrm{~min}$. A small opening in the Perspex box allowed access between both sides of the 
cell. Time spent in and number of entries into the light side was recorded using Activity Monitor software (v.6.02; Med Associates).

\section{Elevated Plus Maze (EPM)}

The apparatus consisted of four $30 \mathrm{~cm}$ long and $6 \mathrm{~cm}$ wide arms extending from a central square $(6 \times 9 \times 6 \mathrm{~cm})$, elevated $39 \mathrm{~cm}$ above the ground. High $(15 \mathrm{~cm})$ walls enclosed two opposing 'closed' arms, while the two opposite arms were 'open'. Mice were placed in the centre of the apparatus, and were allowed to roam freely for $10 \mathrm{~min}$. Movement was tracked from above using Top Scan Lite 2.0 software, and the time spent in the open arms, and the number of entries into the closed and open arms, were assessed.

\section{Spatial Working Memory: Continuous Spontaneous Alternation Test (SAT)}

The SAT was conducted using an enclosed Y-maze, with each arm $10 \mathrm{~cm}$ wide and $30 \mathrm{~cm}$ long, with $17 \mathrm{~cm}$ high walls. The maze was cleaned with water between tests and for testing, mice were placed in the centre of the arena facing the 'home' arm. Mice are allowed free access to the three arms of the maze for a total of $10 \mathrm{~min}$ during which the sequence of arm entries was recorded using Ethovision XT software. From these sequences, proportions of arms entered that were different from those previously entered were calculated to arrive at a percentage alternation score (PAS). An 'alternation' is determined from successive entries of three arms in which three different arms are entered. PAS was calculated by dividing the number of observed alternations by the number of maximum possible alternations (total number of entries -2) and multiplying the quotient by 100 .

\section{Spatial Reference Memory: Appetitive T-maze Test}

Acquisition and reversal learning in a reward-based T-maze (each arm was $7.6 \mathrm{~cm}$ wide and each opposing arm was $26.7 \mathrm{~cm}$ long, with a $28.9 \mathrm{~cm}$ home arm, with $13 \mathrm{~cm}$ high walls) was tested as described (Moy et al., 2007). Acquisition of this task demands the use of allocentric spatial cues and is affected by hippocampal lesions (Deacon et al., 2002; Reisel et al., 2002; von Engelhardt et al., 2008). The maze was surrounded by distal 3-D spatial cues placed $40 \mathrm{~cm}$ above and outside each arm. Before testing, mice were food deprived to $85-90 \%$ of their free-feeding body weight 5 days before testing and throughout the duration of the experiment. Mice were habituated (with 4 trials per day) to the Tmaze and trained to obtain a food reward ( $0.2 \mathrm{~g}$ of chocolate-flavored rice puffs) from cups located at the ends of the two choice arms. Only when the mice could readily run from the start arm to a choice arm and consume their reward was acquisition commenced. After 5 days of habituation, 10 successive trials per day were initiated. One choice arm was designated the 'reward' arm with a food reward $(0.2$ g chocolate-flavored rice puffs) placed at the end of the arm. The reward arm was on the left for half the mice, and on the right for the remainder, and this was randomized between treatment groups. At the beginning of each session, the mouse was placed in a start box at the bottom of the home arm. The start box door was opened, and the mouse was given the choice between entering either arm. 
Following a correct choice the mouse was given time to consume the food reward and then guided back into the start box to begin the next session. If the mouse made an incorrect choice it was left in the maze for $15 \mathrm{~s}$ before being guided back to the start box. To meet criterion, mice were required to make $80 \%$ correct choices for 3 consecutive days before reversal training commenced, in which the reward arm was switched to the opposite arm and 10 trials per day were initiated. Testing was stopped after criterion for individual mice was met during reversal. Time spent in junction before choice were recorded using Ethovision XT software; and the number of correct choices, and number of days to meet criterion were recorded by an observer.

\section{Statistical Analysis}

All graphs and statistical analysis were conducted using Graph Pad Prism (v.6) (GraphPad, La Jolla, CA, USA). All data are expressed as mean \pm SEM. Shapiro-Wilks test were employed to assess the shape of data distributions. For data sets which met the assumptions of normality, comparison of data was performed using either one-way ANOVA or two-way RM ANOVA, followed by appropriate post-hoc comparisons, as described or unpaired t-test. For data sets which did not meet the assumption of normality, the non-parametric equivalent of a t-test, the Mann-Whitney $U$ test was used. Results were considered statistically significant if $p<0.05$.

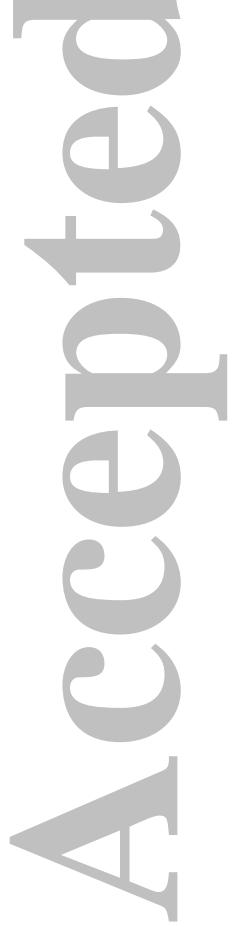




\section{RESULTS}

\section{Distribution of RXFP3 mRNA and RLN3-Positive Innervation in Hippocampus}

In agreement with previous studies in mouse (Smith et al., 2010) and rat (Ma et al., 2009c), the present study identified RXFP3 mRNA expression in mouse hippocampal formation (Fig. 1A) particularly in the DG hilus (Fig. 1B), across the stratum oriens layer of CA1, with less expression in the pyramidal layer of CA1 (Fig. 1C). RXFP3 mRNA was also detected in cells across the pyramidal, stratum oriens and radiatum layers of CA3 (Fig. 1D). Furthermore, the RXFP3 mRNA expression pattern overlapped the distribution of neuronal fibres and terminals containing RLN3-IR in the hippocampus (Fig. 2A), with abundant fibres observed in the DG hilus (Fig. 2B), and similar to RXFP3 mRNA levels, a smaller density of neuronal fibres containing RLN3-IR was observed in the pyramidal layer of CA1 and the stratum oriens of CA1 (Fig. 2C). Dense RLN3-positive fibres were detected across the pyramidal layer and radiatum of CA3 (Fig. 2D).

These results are also in agreement with the distribution of RXFP3 mRNA reported in the Allen Brain Institute atlas of gene expression (Fig. 3A). Notably, the distribution of RXFP3 mRNA and RLN3-positive nerve fibres is similar to that of a proportion or population of $\gamma$-aminobutyric acid (GABA) neurons in the hippocampus, as reflected by the pattern of GAD67 mRNA expression (Fig. 3B), as well as other populations of GABA neurons that express the neuropeptide, SST (Fig. 3C) and the calcium-binding proteins, PV (Fig. 3D) and CR (Fig. 3E), which are co-expressed with GABA in the hippocampus (Freund and Buzsaki, 1996; Jinno and Kosaka, 2002b; Baraban and Tallent, 2004).

\section{RLN3 Innervation of Hippocampal Interneurons}

For the analysis of RLN3-IR in neuronal fibres in relation to other markers of hippocampal neurons, a sequential double and triple label immunohistochemistry protocol was used with RLN3 and GABA, SST and the calcium-binding proteins, PV and CR (Fig. 4). Boutons containing RLN3-IR were observed in apposition to neurons positive for GABA (Fig. 4A), SST, PV (Fig. 4B; Fig. S1) and CR (Fig. 4C); and the number and proportions of the GABA-, SST-, PV- and CR- positive neurons contacted by fibres containing RLN3-IR were counted in the unilateral dorsal hippocampus of a representative coronal section (-2.54 $\mathrm{mm}$ from Bregma), from 3 mice (see Materials and Methods for details), based on the strong RLN3 innervation observed at this level (Table S2).

A high density of SST neurons was detected within the DG hilus and stratum radiatum of CA1 and CA3 with the highest density in the oriens layer of both subfields, and in the material assessed, $\sim 26 \%$ of SST-positive neurons ( $6 \pm 1$ of $23 \pm 3$ neurons counted, $n=3$ ) in the DG hilus received contacts from fibres containing RLN3-IR. Similarly, $\sim 14 \%$ of SST-positive neurons ( $5 \pm 1$ of $34 \pm 6, n$ $=3$ ) in the stratum oriens layer of CA1 and $\sim 33 \%$ of SST-positive neurons $(3 \pm 2$ of $8 \pm 3, n=3)$ in the stratum radiatum of CA3 were contacted by fibres containing RLN3-IR. Furthermore, we observed RLN3-positive bouton contacts on a subpopulation of GABA-positive neurons, representing $\sim 12 \%$ of 
GABA-positive neurons ( $5 \pm 0$ of $46 \pm 11, n=3$ ) in the DG hilus and $\sim 15 \%$ of GABA-positive neurons $(6 \pm 2$ of $38 \pm 9, \mathrm{n}=3)$ in the stratum oriens layer of CA1. Notably, the number of neurons innervated by fibres containing RLN3-IR is similar for both SST and GABA populations with a total of 40 SST-positive neurons and 44 GABA-positive neurons (Table S2).

In contrast, neuronal fibres containing RLN3-IR were observed to innervate a smaller population of PV- and CR-positive neurons in the hippocampus, with $23 \%$ of PV-positive neurons ( $1 \pm 0$ of $4 \pm$ $1, n=3)$ in the DG hilus innervated, and $\sim 7 \%$ of PV-positive neurons $(3 \pm 1$ of $45 \pm 8)$ in the oriens layer of the CA3, and $\sim 7 \%$ of PV-positive neurons (a total of 17 of 268) in all subfields of the hippocampus. Similarly, $\sim 9 \%$ of CR-positive neurons ( $2 \pm 1$ of $23 \pm 4, n=3$ ) in the DG hilus were innervated by fibres containing RLN3-IR, with only $\sim 5 \%$ of CR-positive neurons (a total of 18 of 399, $n=3$ ) innervated in all subfields of the hippocampus, in the material examined (Table S2).

\section{In Vivo Validation of $\mathrm{AAV}^{(1 / 2)}$-Cre-IRES-eGFP and Cre Expression in SST-positive Neurons}

Based on the reported role of SST-positive neurons in the DG hilus in learning and memory (Baratta et al., 2002; Andrews-Zwilling et al., 2010; Spiegel et al., 2013), and the appositions observed between RLN3-positive afferents and SST-positive neurons in the DG hilus, we examined the functional role of RXFP3 in this region by conditionally deleting RXFP3 in the DG hilus in adult floxed-RXFP3 mice using an AAV ${ }^{(1 / 2)}$-Cre-IRES-eGFP viral vector. To validate that the $\mathrm{AAV}^{(1 / 2)}$-CreIRES-eGFP viral vector effectively drove Cre recombinase expression in vivo and transduced hippocampal DG hilus SST-positive neurons, sections from adult floxed-RXFP3 mice (injected bilaterally in the DG hilus with $\mathrm{AAV}^{(1 / 2)}$-Cre-IRES-eGFP) were processed for Cre- and SST-IR. Examination of these sections revealed abundant eGFP (Fig. 5A) and Cre-IR (Fig. 5B) in neurons in the DG hilus. Importantly, Cre-IR was observed in the majority of SST-positive neurons present in the DG hilus of injected mice (Fig. 5C, D; Fig. S2).

\section{Confirmation of Conditional RXFP3 Deletion within the DG Hilus}

Six (6) weeks after bilateral injections of $\mathrm{AAV}^{(1 / 2)}$-Cre-IRES-eGFP into the DG hilus, a significant reduction in RXFP3 mRNA was observed in the DG hilus, relative to control $\mathrm{AAV}^{(1 / 2)}$ eGFP bilaterally injected mice $\left(\mathrm{t}_{(14)}=3.64, p<0.01, n=3-5\right.$ mice per group, Fig. 6A-C). Although Cre-IR was observed in CA3, a significant reduction in RXFP3 mRNA was not observed in this area in $\mathrm{AAV}^{(1 / 2)}$-Cre-IRES-eGFP bilaterally injected mice, relative to control, $\mathrm{AAV}^{(1 / 2)}$-eGFP injected mice $\left(\mathrm{t}_{(14)}=2.06, p=0.058\right.$, Fig. 6D). Therefore, while Cre was present in some CA3 neurons, it is presumed that an insufficient number of RXFP3 mRNA-positive neurons were transduced to produce a detectible decrease in mRNA levels. Viral spread was observed along the rostrocaudal extent of the dorsal DG hilus and CA3 in AAV ${ }^{(1 / 2)}$-Cre-IRES-eGFP treated mice, but did not reach the ventral DG hilus/CA3 regions (Fig. 6E). 


\section{RXFP3 Deletion from DG Hilus Impaired Spatial Reference Memory in an Appetitive T-maze} Task

In an appetitive $\mathrm{T}$-maze task, $\mathrm{AAV}^{(1 / 2)}$-Cre-IRES-eGFP-treated mice made significantly fewer correct choices compared to $\mathrm{AAV}^{(1 / 2)}$-eGFP-treated control mice, but a significant increase in performance over days tested was observed in both groups (RM 2-way ANOVA, main effect of treatment, $\mathrm{F}_{(1,21)}=9.18, p=0.0064$; main effect of day, $\mathrm{F}_{(4,84)}=32.6, p<0.0001$; treatment $\times$ day interaction, $\mathrm{F}_{(4,84)}=1.89, p=0.120$; Bonferroni post hoc analysis between treatments within days 1-3, $p<0.05$, Fig. 7A). Although mice from both treatment groups met the criterion of $80 \%$ correct choices for 3 consecutive days, $\mathrm{AAV}^{(1 / 2)}$-Cre-IRES-eGFP mice took significantly longer to meet the criterion than $\mathrm{AAV}^{(1 / 2)}-\mathrm{eGFP}$ mice $(\mathrm{U}=35, p=0.0210$, Fig. 7B).

When the criterion of correct choices was met during acquisition, the reward arm was swapped to the opposite arm, and reversal learning was commenced. This was done to test whether $\mathrm{AAV}^{(1 / 2)}$-CreIRES-eGFP-treated mice displayed a resistance to alter/change a learned behavior (i.e., altered behavioral flexibility). Two-way repeated measures ANOVA did not reveal a main effect of treatment $\left(\mathrm{F}_{(1,20)}=1.79, p=0.196\right)$, nor an interaction effect $\left(\mathrm{F}_{(4,80)}=0.403, p=0.806\right)$ in \% correct choice during reversal, however a main effect of day was observed $\left(\mathrm{F}_{(1,24)}=4.46, p=0.045\right.$, Fig. 7A). Interestingly, during reversal, $\mathrm{AAV}^{(1 / 2)}$-Cre-IRES-eGFP mice spent significantly more time in the $\mathrm{T}$ maze centre junction before making a choice. No differences were observed between groups in time taken to meet the learning response criterion $(\mathrm{U}=66.5, p=0.780$, Fig. 7B $)$.

RXFP3 Deletion from DG Hilus Impaired Spatial Working Memory in a Continuous SAT in a Y-maze

In studies to measure spatial working memory, mice were assessed in a continuous SAT in a Ymaze. RXFP3 deletion in the DG hilus significantly impaired spontaneous alternation in the percent alternation score (PAS) in the first 1-min time bin $\left(\mathrm{t}_{(22)}=3.92, p=0.0007\right.$, Fig. 8), with a PAS score of $67.6 \%$ for $\mathrm{AAV}^{(1 / 2)}$-eGFP-treated controls, and $35.8 \%$ for AAV ${ }^{(1 / 2)}$-Cre-IRES-eGFP-treated mice. A ttest revealed $\mathrm{AAV}^{(1 / 2)}$-eGFP mice performed significantly better than chance (PAS 50\%) $\left(\mathrm{t}_{(24)}=3.02, p\right.$ $=0.0059)$, relative to $\mathrm{AAV}^{(1 / 2)}$-Cre-IRES-eGFP mice that performed significantly below chance $\left(\mathrm{t}_{(24)}=\right.$ 2.26, $p=0.0329$ ) in the first $\min$ of the SAT test. However, over a total test time of $3 \mathrm{~min}$, a significant difference between treatments was not observed $\left(\mathrm{t}_{(22)}=1.18, p=0.0822\right)$, with control mice performance only just above chance (PAS, $52.1 \pm 3.35 ; \mathrm{t}_{(24)}=0.630, p=0.536$ ), and poorer performance observed for $\mathrm{AAV}^{(1 / 2)}$-Cre-IRES-eGFP mice (PAS, $\left.44.8 \pm 3.54 ; \mathrm{t}_{(25)}=1.80, p=0.0844\right)$.

\section{RXFP3 Deletion from DG Hilus Did Not Alter Learning and Long-term Memory Retention in a} Morris Water Maze

We next determined whether deletion of RXFP3 from the DG hilus impaired spatial learning and long-term retrieval in a MWM. A 2-way repeated measures ANOVA revealed a significant main 
effect of day $\left(\mathrm{F}_{(5,110)}=35.4, p=<0.0001\right)$, but no main effect of treatment was observed $\left(\mathrm{F}_{(1,22)}=\right.$ $0.0240, p=0.878)$, nor an interaction $\left(\mathrm{F}_{(5,110)}=0.272, p=0.928\right.$, Fig. 9A) in the latency (s) to locate the hidden platform during acquisition. Twenty-four (24) $\mathrm{h}$ after the last acquisition day, in the probe trial, both treatment groups spent significantly more time in the target quadrant relative to the other quadrants in the first 1 min time bin (one-way ANOVA, $\mathrm{F}_{(7,84)}=11.3, p<0.0001$ ) and in the total duration of 2 min (one-way ANOVA, $\mathrm{F}_{(7,84)}=29.2, p<0.0001$, Fig. 9B). Bonferroni's planned comparison tests confirmed that both $\mathrm{AAV}^{(1 / 2)}$-Cre-IRES-eGFP-treated mice and $\mathrm{AAV}^{(1 / 2)}$-eGFPtreated control mice spent significantly more percent time in the target quadrant than in the adjacent quadrant to the right ( $\mathrm{AAV}^{(1 / 2)}$-eGFP; $p<0.0001$, $\mathrm{AAV}^{(1 / 2)}$-Cre-IRES-eGFP; $p<0.05$ ), the adjacent quadrant to the left $(p<0.0001)$ and to the opposite quadrant $(p<0.0001)$. No significant differences were observed between treatment groups in the percent time spent in the target quadrant in the first $\min \left(\mathrm{t}_{(21)}=0.0605, p=0.952\right)$ and the total $2 \min$ test duration $\left(\mathrm{t}_{(21)}=1.009, p=0.325\right)$. The time each group spent in the target quadrant on probe day was compared with a 'chance' value of $30 \mathrm{~s}$ (i.e., the

amount of time a mouse would be expected to spend in the target quadrant over a total duration of 2 min if no spatial memory had been formed). Both groups spent significantly more than $25 \%$ (15 s) of their time in the target quadrant in the first min $\left(\mathrm{AAV}^{(1 / 2)}-\mathrm{GFP}, \mathrm{t}_{(24)}=3.91, p=0.0007 ; \mathrm{AAV}^{(1 / 2)}-\mathrm{Cre}\right.$, $\mathrm{t}_{(24)}=4.01, p=0.0005$ and significantly more than $25 \%(30 \mathrm{~s})$ of their time in the target quadrant in the total 2 min duration $\left(\mathrm{AAV}^{(1 / 2)}-\mathrm{GFP}, \mathrm{t}_{(24)}=5.80, p<0.0001 ; \mathrm{AAV}^{(1 / 2)}-\mathrm{Cre}, \mathrm{t}_{(24)}=4.00, p=0.0005\right)$, suggesting intact spatial long-term memory on probe day.

\section{RXFP3 Deletion from DG Hilus Did Not Alter General Locomotor Activity or Innate Anxiety in} an EPM and L/D box

No differential effects were observed between treatments in the total distance travelled in a locomotor cell 21 days after viral injections $\left(\mathrm{t}_{(23)}=0.551, p=0.587\right.$; Table S3). This result was consistent across 5-min bins within a total duration of $1 \mathrm{~h}$, and both groups significantly decreased their distance travelled over time (RM 2-way ANOVA, main effect of treatment $\left(\mathrm{F}_{(1,23)}=0.303, p=\right.$ $0.587)$; time $\left(\mathrm{F}_{(11,253)}=15.6, p<0.0001\right)$; treatment $\times$ time interaction $\left(\mathrm{F}_{(11,253)}=0.520, p=0.889\right)$.

Twenty-four (24) $\mathrm{h}$ after the probe day in the MWM, the different groups of mice were tested in an EPM to measure stress-induced anxiety-like behavior. RXFP3 deletion from DG hilus did not induce any changes relative to $\mathrm{AAV}^{(1 / 2)}$-GFP control mice in the time spent in the open arms $\left(\mathrm{t}_{(23)}=\right.$ 0.886, $p=0.139$; Table S3), or the number of entries into the open arms $\left(t_{(23)}=0.498, p=0.623\right)$. Similarly, in the L/D box, no differences were observed between groups in the total time spent in the light side $\left(\mathrm{t}_{(22)}=0.886, p=0.385\right.$; Table S3) or entries into the light side $\left(\mathrm{t}_{(22)}=1.528, p=0.141\right)$. 


\section{DISCUSSION}

In the present study, in light of the distinct topography of RXFP3 mRNA in the mouse hippocampus, we conducted a histochemical analysis of the possible association of RLN3-positive nerve fibres with some established hippocampal neuron types; and a behavioral analysis of mice after deletion of RXFP3 from the DG hilus. The main findings were firstly, that RXFP3 mRNA was confirmed to be expressed in distinct layers of the hippocampus, with strong expression in neurons within the DG hilus, and non-principal neurons located within the pyramidal and stratum oriens layer of CA1 and across the pyramidal layer, stratum oriens and radiatum of CA3. Interestingly, neuronal fibres and terminals containing RLN3-IR were identified making consistent putative close contacts with GABA- and SST- positive neurons and, to a lesser degree, contacts with PV- and CR-positive neurons. Secondly, in this first study to manipulate RLN3/RXFP3 signaling within the hippocampus by deletion of RXFP3 from the DG hilus, we observed a strong and consistent deficiency in an appetitive reference memory task in a T-maze, and impairment in spatial working memory in a Ymaze SAT test. In contrast, deletion of RXFP3 from the DG hilus did not affect the ability of mice to learn and acquire the location of a hidden platform in a MWM test of long-term memory retention. Furthermore, hilar RXFP3 deletion did not alter anxiety-like behavior in an EPM or L/D box. Overall, this study identified key behavioral consequences of RXFP3 depletion from DG hilus and the neurochemical phenotype of the RLN3/RXFP3 targeted neurons in the hippocampus, providing new insights into the complex role of this modulatory neuropeptide system in learning and memory.

Our first goal was to assess the neurochemical anatomy of the RLN3/RXFP3 system within the hippocampus. A detailed mapping of the distribution of RXFP3 mRNA/binding sites and RLN3-IR has been completed in mouse (Smith et al., 2010), rat (Ma et al., 2009c; Olucha-Bordonau et al., 2012) and non-human primate (Ma et al., 2009c) brain and the results are consistent with the present analysis in the mouse hippocampus. Based on the overlap between the quite restricted topographic distribution of neurons expressing RXFP3 mRNA with the more extensive distribution of GABAergic interneurons, we hypothesized that RXFP3 is expressed by a subpopulation of GABA neurons in the hippocampus. This in turn predicted that neuronal fibres expressing RLN3-IR would make close contacts with GABA-positive neurons in the hippocampus, particularly in the DG hilus and the oriens layer of CA1, and this was demonstrated experimentally. Notably, RLN3-positive fibres were also

found to make a significant number of contacts with SST-positive neurons in these areas. As the majority of SST neurons ( 90\%) in the DG hilus co-express GABA (Kosaka et al., 1988), our results indicate there is a subpopulation of RXFP3-positive neurons which co-express both GABA and SST in the hippocampus. Interestingly, RLN3-positive fibres and terminals were also observed to make close contacts with PV- and CR-positive neurons in the hippocampus, but their incidence was approximately half that for contacts with GABA- and SST-positive neurons. PV and CR label distinct, nonoverlapping subsets of inhibitory hippocampal interneurons (Xu et al., 2010), therefore, it is likely that 
a majority of RXFP3-positive neurons in the hippocampus express GABA and SST, while nonoverlapping smaller subpopulations of RXFP3-positive neurons co-express PV or CR.

SST neurons constitute one of the largest groups of GABA neurons within the DG, with all these SST-positive neurons located within the hilus (Scharfman and Myers, 2012). Retrograde tracing studies in mice indicate that a large proportion (44\%) of SST-positive neurons in the DG hilus project to the septal region (Zappone and Sloviter, 2001; Jinno and Kosaka, 2002a), and directly innervate GABAergic and cholinergic neurons in that region (Toth et al., 1993; Gulyas et al., 2003). In turn, SST hippocampal-septal neurons are reciprocally innervated by cholinergic and GABAergic septal neurons (Freund and Antal, 1988; Freund and Buzsaki, 1996). The high percentage of SST DG hilus neurons that innervate the septum and the high incidence of RLN3 inputs to SST- and GABA-positive neurons in the DG hilus, suggest RLN3/RXFP3 signaling plays an important role in the hippocamposeptal and septo-hippocampal circuitry, modulating cognition and learning and memory. Therefore, it will be of interest to further investigate the precise anatomical connectivity of those neurons and circuits influenced by the RLN3/RXFP3 system and its resultant functional impact.

However, there is a considerable amount of existing evidence regarding the functional role of SST-containing DG hilus interneurons that might inform the possible effects of RXFP3 signaling on hippocampal activity. Activation of SST DG hilus interneurons reduces long-term potentiation (LTP) in the mouse DG (Baratta et al., 2002), a cellular process involved in learning and memory; and an age-dependent reduction in SST and GAD67 DG hilus neurons in apolipoprotein E4 (apoE4) knock-in mice correlated with learning and memory deficits in the MWM test (Andrews-Zwilling et al., 2010). Notably, a similar result was observed in a study of rat DG hilus neurons (Spiegel et al., 2013). In early studies, global depletion of SST in rats by cysteamine hydrochloride, a somatostatin inhibiting agent, impaired learning and memory in a passive avoidance task (Yamazaki et al., 1996); and similar studies have shown impairment in spatial discrimination in mice (Guillou et al., 1998; Epelbaum et al., 2009; Tuboly and Vecsei, 2013). Interestingly, optogenetic inhibition of GABAergic DG hilus interneuron activity impairs spatial learning and memory retrieval (Andrews-Zwilling et al., 2012), although this effect was via the entire GABA interneuron population with no implicit selectivity for SST/GABA neurons. Multiple studies have reported that SST interneurons inhibit excitatory synaptic transmission excitability, resulting in silencing or hyperpolarization in hippocampus (see (Liguz-

Lecznar et al., 2016) for review); and increases in inhibition (of hippocampal interneurons) is wellknown to be an important cellular mechanism in learning and memory (McEchron and Disterhoft, 1997; Knott et al., 2002; Ruediger et al., 2011). In more recent studies, an enhancement in inhibition onto CA1 pyramidal neurons during learning in a trace eye blink conditioning task, was found to be mediated by an increase in intrinsic excitability of SST interneurons in mice and rats (McKay et al., 2013), and inactivating SST dendrite-targeting interneurons during aversive stimuli increased CA1 pyramidal cell population responses and prevented fear learning in mice (Lovett-Barron et al., 2014). 
Therefore, our second goal was to assess the behavioral effects of Cre-recombinase-induced local deletion of RXFP3 in the DG hilus of adult floxed-RXFP3 mice. In these studies we observed a strong and consistent deficiency in the performance of $\mathrm{AAV}^{(1 / 2)}$-Cre-IRES-eGFP-treated floxed-RXFP3 mice in an appetitive reference memory task in a T-maze. In a continuous spontaneous alternation Y-maze task, RXFP3-depleted mice made fewer alternations in the first min of the task, suggesting impairment in spatial working memory. In terms of the functional implications of these findings, it is proposed that the RLN3-containing inputs to the GABA/SST-positive neurons and other GABA neuron populations in the DG hilus can regulate hippocampal and cognitive processing. If this is the case, depletion of RXFP3 from GABA and/or GABA/SST neurons in the DG hilus may disrupt disinhibition of target neurons, and weaken synaptic inhibition of excitatory neurons, a key component in compromised cognitive processes. This, in turn, could produce impaired learning and memory, via effects within the directly targeted hippocampus and via remote, relayed effects in the MS/DB. Further studies are required to explore this hypothesis, including an examination of the effect of RXFP3 activation by validated RXFP3-specific agonist peptides (Liu et al., 2005; Shabanpoor et al., 2012; Zhang et al., 2015) on DG hilus SST neuron activity, perhaps in a convenient strain of SST reporter mice (Ma et al., 2006; Peng et al., 2013).

In contrast to these effects, however, a deficiency in spatial learning and long-term memory was not observed based on the performance of $\mathrm{AAV}^{(1 / 2)-} \mathrm{Cre-IRES-eGFP-treated} \mathrm{floxed-RXFP3} \mathrm{mice} \mathrm{in} \mathrm{the}$ MWM. The differences observed in these tests of memory retention suggest a specific role for hilar RLN3/RXFP3 signaling in learning and memory that may reflect the different neurochemical and psychological processes involved in acquiring memory. Optimal performance in the MWM requires the use of allocentric strategies where distal cues provide a geometric reference to an animal's current location and this form of memory consolidation is primarily hippocampal-dependent (Vorhees and Williams, 2006; Garthe et al., 2009). While effective performance in the appetitive T-maze task also requires the use of hippocampal-dependent allocentric strategies whereby the animal is rewarded for choosing a constant, designated goal arm on the basis of its spatial location (Deacon et al., 2002; Reisel et al., 2002; Sanderson et al., 2008; von Engelhardt et al., 2008), differences in memory consolidation between these two spatial reference memory tests have been highlighted (Hodges, 1996; Deacon et al., 2002; Bannerman et al., 2012). The most prominent refers to the distinct differences in the motivational aspect of both tasks. The MWM is motivated by the desire to escape onto a safe platform, whereas the appetitive T-maze is motivated by food reward. Therefore, differences in reinforcement may affect the strategy adopted and activate different brain circuits involved in motivation and reward. Furthermore, although both tests require the use of allocentric strategies, the appetitive T-maze requires the mouse to use spatial information to guide selection between two alternative responses and to learn to make a constant body turn for a food reward. Taken together, the results from the present study suggest RXFP3 in the DG hilus is not essential for spatial tasks that rely 
solely on the use of allocentric spatial maps, but may influence tasks which integrate multiple strategies for using spatial information to guide selection between alternative responses that lead to a reinforcing reward. Moreover, in regard to the contradictory effects observed in the spontaneous alternation Y-maze task and MWM in the present study, spontaneous alternation has been shown to be a more reliable measure in detecting hippocampal dysfunction than the commonly used MWM (Rawlins and Olton, 1982; Reisel et al., 2002; Deacon and Rawlins, 2005). Although both tasks detect spatial memory deficits in mice with whole lesions of the hippocampus (Morris et al., 1982; Lalonde, 2002; Deacon and Rawlins, 2005), consistent with the results from the present study, a deficit in spatial memory following deletion of the GluR-A (GluR1) AMPA receptor subunit was only detected in a spontaneous alternation T-maze task, whereas spatial reference memory was not affected in a MWM (Reisel et al., 2002).

In a continuous SAT in a Y-maze, mice with RXFP3 depleted from the DG hilus displayed significantly lower rates of alternation (PAS, 36\%) relative to control mice (PAS, 68\%) in the first minute of the task, demonstrating an impairment in spatial working memory. After 3 min, DG hilus RXFP3 depleted mice still displayed low rates of alternation (PAS 47\%), but the control mice had similar rates (PAS, 52\%), suggesting poor spatial working memory performance in both treatment groups. However, the weak performance of the control group assessed over a 3-min session is not surprising. The continuous nature of the task means there is considerable inter-trial interference, a likely reason for low rates of performance in both T-maze (Gerlai et al., 1994) and Y-maze (Hsiao et al., 1996; Deacon et al., 2002) tasks (for review see, Deacon and Rawlins, 2006). Therefore, the decline in PAS observed over the subsequent 2 and 3 min time bins in both treatment groups is likely due to methodological issues associated with the task, whereby the first min is the period in which the most reliable measures are observed.

Lastly, RXFP3 depletion from the DG hilus did not alter anxiety-like behavior in an EPM or L/D box, tested 1 and 3 days, respectively, after the MWM test with its associated swim stress (Engelmann et al., 2006). In the mice studied, we observed $\mathrm{AAV}^{(1 / 2)}$ spread along the rostral-caudal length of the DG hilus and CA3, including part of the ventral hippocampus, which is functionally implicated in the control of emotion and affect, and wherein RLN3-positive nerve fibres and RXFP3 mRNA are abundant (Ma et al., 2009b; Smith et al., 2010). However, the viral injections in the present study did not cover the entire dorsoventral extent of the DG hilus in ventral hippocampus, reducing the likelihood of observing an effect on anxiety-like behavior. The RLN3/RXFP3 system in mice and rats has been shown to be involved in stress responses (Tanaka et al., 2005; Banerjee et al., 2010) and modulation of anxiety-like behavior (Ryan et al., 2013; Zhang et al., 2015), with pronounced changes in RLN3 mRNA expression and RLN3-IR levels in response to stressors (Tanaka et al., 2005; Lenglos et al., 2013; Ma et al., 2013; Walker et al., 2015; Calvez et al., 2016). Therefore, further studies with more extensive and/or focused depletion of RXFP3 in ventral hippocampus are warranted. 


\section{Conclusions}

The anatomical distribution of the RLN3/RXFP3 system in the major nodes of the septohippocampal system (Ma et al., 2009c; Smith et al., 2010; Olucha-Bordonau et al., 2012) suggests it contributes to important neuronal circuits in cognition, and learning and memory. This first study to investigate the specific role of RLN3/RXFP3 signaling in the mouse hippocampus has demonstrated neuronal contacts with distinct populations of GABAergic neurons in the hippocampus, and that depletion of RXFP3 within the DG hilus can produce impairments in spatial reference and working memory in an appetitive T-maze and spontaneous alternation task in a Y-maze, respectively. These data suggest that the RLN3-containing pathway from the NI to the hippocampus can mediate inhibitory control of local and septal target neurons via RXFP3, and modulate memory processes.

\section{Acknowledgments}

The authors thank Timothy Lovenberg and Steve Sutton (Janssen Companies of Johnson \& Johnson, La Jolla, CA, USA) for commissioning and providing the floxed-RXFP3 mice; Sharon Layfield for the production of viral vectors; Verena Wimmer for technical assistance with immunohistochemistry and confocal imaging; and the Core Animal Services at The Florey Institute of Neuroscience and Mental Health for the maintenance of the floxed-RXFP3 mouse colony. The authors declare that there is no conflict of interest.

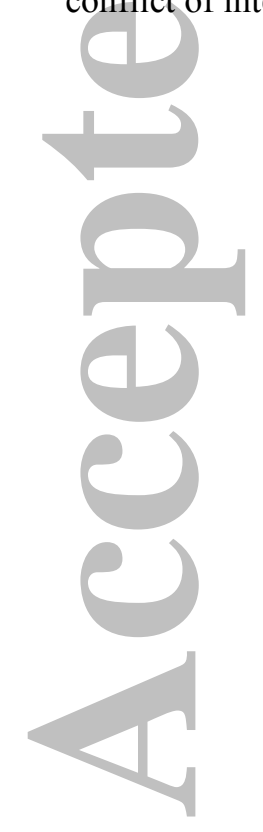

John Wiley \& Sons

This article is protected by copyright. All rights reserved. 


\section{References}

Amaral DG, Scharfman HE, Lavenex P. 2007. The dentate gyrus: fundamental neuroanatomical organization (dentate gyrus for dummies). Prog Brain Res 163:3-22.

Andrews-Zwilling Y, Bien-Ly N, Xu Q, Li G, Bernardo A, Yoon SY, Zwilling D, Yan TX, Chen L, Huang Y. 2010. Apolipoprotein E4 causes age- and Tau-dependent impairment of GABAergic interneurons, leading to learning and memory deficits in mice. J Neurosci 30:13707-13717.

Andrews-Zwilling Y, Gillespie AK, Kravitz AV, Nelson AB, Devidze N, Lo I, Yoon SY, Bien-Ly N, Ring K, Zwilling D and others. 2012. Hilar GABAergic interneuron activity controls spatial learning and memory retrieval. PLoS One 7:e40555.

Banerjee A, Shen PJ, Ma S, Bathgate RA, Gundlach AL. 2010. Swim stress excitation of nucleus incertus and rapid induction of relaxin-3 expression via CRF1 activation. Neuropharmacology 58:145-155.

Bannerman DM, Bus T, Taylor A, Sanderson DJ, Schwarz I, Jensen V, Hvalby O, Rawlins JN, Seeburg PH, Sprengel R. 2012. Dissecting spatial knowledge from spatial choice by hippocampal NMDA receptor deletion. Nat Neurosci 15:1153-1159.

Bannerman DM, Rawlins JN, McHugh SB, Deacon RM, Yee BK, Bast T, Zhang WN, Pothuizen HH, Feldon J. 2004. Regional dissociations within the hippocampus - memory and anxiety. Neurosci Biobehav Rev 28:273-283.

Baraban SC, Tallent MK. 2004. Interneuron diversity series: Interneuronal neuropeptides endogenous regulators of neuronal excitability. Trends Neurosci 27:135-142.

Baratta MV, Lamp T, Tallent MK. 2002. Somatostatin depresses long-term potentiation and $\mathrm{Ca}^{2+}$ signaling in mouse dentate gyrus. J Neurophysiol 88:3078-3086.

Bassant MH, Poindessous-Jazat F. 2001. Ventral tegmental nucleus of Gudden: a pontine hippocampal theta generator? Hippocampus 11:809-813.

Bassant MH, Poindessous-Jazat F. 2002. Sleep-related increase in activity of mesopontine neurons in old rats. Neurobiol Aging 23:615-624.

Bathgate RAD, Lin F, Hanson NF, Otvos L, Jr., Guidolin A, Giannakis C, Bastiras S, Layfield SL,

Ferraro T, Ma S and others. 2006. Relaxin-3: improved synthesis strategy and demonstration of its high-affinity interaction with the relaxin receptor LGR7 both in vitro and in vivo. Biochemistry 45:1043-1053.

Bathgate RAD, Samuel CS, Burazin TCD, Layfield S, Claasz AA, Reytomas IG, Dawson NF, Zhao C, Bond C, Summers RJ and others. 2002. Human relaxin gene 3 (H3) and the equivalent mouse relaxin (M3) gene. Novel members of the relaxin peptide family. J Biol Chem 277:1148-1157.

Brown RE, McKenna JT. 2015. Turning a negative into a positive: Ascending GABAergic control of cortical activation and arousal. Front Neurol 6:135.

Burazin TCD, Bathgate RAD, Macris M, Layfield S, Gundlach AL, Tregear GW. 2002. Restricted, but abundant, expression of the novel rat gene-3 (R3) relaxin in the dorsal tegmental region of brain. Journal of Neurochemistry 82:1553-1557.

Burgess N, Maguire EA, O'Keefe J. 2002. The human hippocampus and spatial and episodic memory. Neuron 35:625-641.

Calvez J, de Avila C, Matte LO, Guevremont G, Gundlach AL, Timofeeva E. 2016. Role of relaxin3/RXFP3 system in stress-induced binge-like eating in female rats. Neuropharmacology 102:207215.

Deacon RM, Bannerman DM, Kirby BP, Croucher A, Rawlins JN. 2002. Effects of cytotoxic hippocampal lesions in mice on a cognitive test battery. Behav Brain Res 133:57-68.

Deacon RM, Rawlins JN. 2005. Hippocampal lesions, species-typical behaviours and anxiety in mice. Behav Brain Res 156:241-249.

Deacon RM, Rawlins JN. 2006. T-maze alternation in the rodent. Nat Protoc 1:7-12.

Dutar P, Bassant MH, Senut MC, Lamour Y. 1995. The septohippocampal pathway: structure and function of a central cholinergic system. Physiol Rev 75:393-427.

Engelmann M, Ebner K, Landgraf R, Wotjak CT. 2006. Effects of Morris water maze testing on the neuroendocrine stress response and intrahypothalamic release of vasopressin and oxytocin in the rat. Horm Behav 50:496-501. 
Epelbaum J, Guillou JL, Gastambide F, Hoyer D, Duron E, Viollet C. 2009. Somatostatin, Alzheimer's disease and cognition: an old story coming of age? Prog Neurobiol 89:153-161.

Freund TF, Antal M. 1988. GABA-containing neurons in the septum control inhibitory interneurons in the hippocampus. Nature 336:170-173.

Freund TF, Buzsaki G. 1996. Interneurons of the hippocampus. Hippocampus 6:347-470.

Ganella DE, Callander GE, Ma S, Bye CR, Gundlach AL, Bathgate RAD. 2013. Modulation of feeding by chronic rAAV expression of a relaxin-3 peptide agonist in rat hypothalamus. Gene Ther 20:703-716.

Garthe A, Behr J, Kempermann G. 2009. Adult-generated hippocampal neurons allow the flexible use of spatially precise learning strategies. PLoS One 4:e5464.

Gerlai R, Marks A, Roder J. 1994. T-maze spontaneous alternation rate is decreased in S100 beta transgenic mice. Behav Neurosci 108:100-106.

Goto M, Swanson LW, Canteras NS. 2001. Connections of the nucleus incertus. J Comp Neurol 438:86-122.

Guillou JL, Micheau J, Jaffard R. 1998. The opposite effects of cysteamine on the acquisition of two different tasks in mice are associated with bidirectional testing-induced changes in hippocampal adenylyl cyclase activity. Behav Neurosci 112:900-908.

Gulyas AI, Hajos N, Katona I, Freund TF. 2003. Interneurons are the local targets of hippocampal inhibitory cells which project to the medial septum. Eur J Neurosci 17:1861-1872.

Hodges H. 1996. Maze procedures: the radial-arm and water maze compared. Brain Res Cogn Brain Res 3:167-181.

Hsiao K, Chapman P, Nilsen S, Eckman C, Harigaya Y, Younkin S, Yang F, Cole G. 1996. Correlative memory deficits, Abeta elevation, and amyloid plaques in transgenic mice. Science 274:99-102.

Jinno S, Kosaka T. 2002a. Immunocytochemical characterization of hippocamposeptal projecting GABAergic nonprincipal neurons in the mouse brain: a retrograde labeling study. Brain Res 945:219-231.

Jinno S, Kosaka T. 2002b. Patterns of expression of calcium binding proteins and neuronal nitric oxide synthase in different populations of hippocampal GABAergic neurons in mice. J Comp Neurol 449:1-25.

Kizawa H, Nishi K, Ishibashi Y, Harada M, Asano T, Ito Y, Suzuki N, Hinuma S, Fujisawa Y, Onda $\mathrm{H}$ and others. 2003. Production of recombinant human relaxin 3 in AtT20 cells. Regul Pept 113:79-84.

Knott GW, Quairiaux C, Genoud C, Welker E. 2002. Formation of dendritic spines with GABAergic synapses induced by whisker stimulation in adult mice. Neuron 34:265-273.

Kocsis B, Di Prisco GV, Vertes RP. 2001. Theta synchronization in the limbic system: the role of Gudden's tegmental nuclei. Eur J Neurosci 13:381-388.

Kocsis B, Vertes RP. 1997. Phase relations of rhythmic neuronal firing in the supramammillary nucleus and mammillary body to the hippocampal theta activity in urethane anesthetized rats. Hippocampus 7:204-214.

Kosaka T, Wu JY, Benoit R. 1988. GABAergic neurons containing somatostatin-like immunoreactivity in the rat hippocampus and dentate gyrus. Exp Brain Res 71:388-398.

Kuei C, Sutton S, Bonaventure P, Pudiak C, Shelton J, Zhu J, Nepomuceno D, Wu J, Chen J, Kamme $\mathrm{F}$ and others. 2007. R3(B $\Delta 23-27) \mathrm{R} / \mathrm{I} 5$ chimeric peptide, a selective antagonist for GPCR135 and GPCR142 over relaxin receptor LGR7: in vitro and in vivo characterization. J Biol Chem 282:25425-25435.

Lalonde R. 2002. The neurobiological basis of spontaneous alternation. Neurosci Biobehav Rev 26:91-104.

Lenglos C, Calvez J, Timofeeva E. 2015. Sex-specific effects of relaxin-3 on food intake and brain expression of corticotropin-releasing factor in rats. Endocrinology 156:523-533.

Lenglos C, Mitra A, Guevremont G, Timofeeva E. 2013. Sex differences in the effects of chronic stress and food restriction on body weight gain and brain expression of CRF and relaxin-3 in rats. Genes Brain Behav 12:370-387.

Lenglos C, Mitra A, Guevremont G, Timofeeva E. 2014. Regulation of expression of relaxin-3 and its receptor RXFP3 in the brain of diet-induced obese rats. Neuropeptides 48:119-132. 
Leutgeb S, Leutgeb JK, Moser MB, Moser EI. 2005. Place cells, spatial maps and the population code for memory. Curr Opin Neurobiol 15:738-746.

Liguz-Lecznar M, Urban-Ciecko J, Kossut M. 2016. Somatostatin and somatostatin-containing neurons in shaping neuronal activity and plasticity. Front Neural Circuits 10:48.

Liu C, Chen J, Kuei C, Sutton S, Nepomuceno D, Bonaventure P, Lovenberg TW. 2005. Relaxin3/insulin-like peptide 5 chimeric peptide, a selective ligand for $\mathrm{G}$ protein-coupled receptor (GPCR)135 and GPCR142 over leucine-rich repeat-containing G protein-coupled receptor 7. Mol Pharmacol 67:231-240.

Liu C, Eriste E, Sutton S, Chen J, Roland B, Kuei C, Farmer N, Jornvall H, Sillard R, Lovenberg TW. 2003. Identification of relaxin-3/INSL7 as an endogenous ligand for the orphan G-proteincoupled receptor GPCR135. J Biol Chem 278:50754-50764.

Lovett-Barron M, Kaifosh P, Kheirbek MA, Danielson N, Zaremba JD, Reardon TR, Turi GF, Hen R, Zemelman BV, Losonczy A. 2014. Dendritic inhibition in the hippocampus supports fear learning. Science 343:857-863.

Lubenov EV, Siapas AG. 2009. Hippocampal theta oscillations are travelling waves. Nature 459:534539.

Ma S, Blasiak A, Olucha-Bordonau FE, Verberne AJ, Gundlach AL. 2013. Heterogeneous responses of nucleus incertus neurons to corticotrophin-releasing factor and coherent activity with hippocampal theta rhythm in the rat. J Physiol (Lond) 591:3981-4001.

Ma S, Bonaventure P, Ferraro T, Shen PJ, Burazin TC, Bathgate RA, Liu C, Tregear GW, Sutton SW, Gundlach AL. 2007. Relaxin-3 in GABA projection neurons of nucleus incertus suggests widespread influence on forebrain circuits via G-protein-coupled receptor-135 in the rat. Neuroscience 144:165-190.

Ma S, Olucha-Bordonau FE, Hossain MA, Lin F, Kuei C, Liu C, Wade JD, Sutton SW, Nunez A, Gundlach AL. 2009a. Modulation of hippocampal theta oscillations and spatial memory by relaxin-3 neurons of the nucleus incertus. Learn Mem 16:730-742.

Ma S, Sang Q, Lanciego JL, Gundlach AL. 2009b. Localization of relaxin-3 in brain of Macaca fascicularis: identification of a nucleus incertus in primate. J Comp Neurol 517:856-872.

Ma S, Shen PJ, Sang Q, Lanciego JL, Gundlach AL. 2009c. Distribution of relaxin-3 mRNA and immunoreactivity and RXFP3-binding sites in the brain of the macaque, Macaca fascicularis. Ann N Y Acad Sci 1160:256-258.

Ma Y, Hu H, Berrebi AS, Mathers PH, Agmon A. 2006. Distinct subtypes of somatostatin-containing neocortical interneurons revealed in transgenic mice. J Neurosci 26:5069-5082.

Martin J, Timofeeva E. 2010. Intermittent access to sucrose increases sucrose-licking activity and attenuates restraint stress-induced activation of the lateral septum. Am J Physiol Regul Integr Comp Physiol 298:R1383-1398.

McEchron MD, Disterhoft JF. 1997. Sequence of single neuron changes in CA1 hippocampus of rabbits during acquisition of trace eyeblink conditioned responses. J Neurophysiol 78:1030-1044.

McKay BM, Oh MM, Disterhoft JF. 2013. Learning increases intrinsic excitability of hippocampal interneurons. J Neurosci 33:5499-5506.

Morris RG, Garrud P, Rawlins JN, O'Keefe J. 1982. Place navigation impaired in rats with hippocampal lesions. Nature 297:681-683.

Moy SS, Nadler JJ, Young NB, Perez A, Holloway LP, Barbaro RP, Barbaro JR, Wilson LM, Threadgill DW, Lauder JM and others. 2007. Mouse behavioral tasks relevant to autism: phenotypes of 10 inbred strains. Behav Brain Res 176:4-20.

Nategh M, Nikseresht S, Khodagholi F, Motamedi F. 2015. Nucleus incertus inactivation impairs spatial learning and memory in rats. Physiol Behav 139:112-120.

Nategh M, Nikseresht S, Khodagholi F, Motamedi F. 2016. Inactivation of nucleus incertus impairs passive avoidance learning and long term potentiation of the population spike in the perforant path-dentate gyrus evoked field potentials in rats. Neurobiol Learn Mem 130:185-193.

Nunez A, Cervera-Ferri A, Olucha-Bordonau F, Ruiz-Torner A, Teruel V. 2006. Nucleus incertus contribution to hippocampal theta rhythm generation. Eur J Neurosci 23:2731-2738.

O'Keefe J. 1993. Hippocampus, theta, and spatial memory. Curr Opin Neurobiol 3:917-924.

O'Keefe J, Nadel L. 1978. The hippocampus as a cognitive map. Clarendon Press, Oxford. 
Olucha-Bordonau FE, Otero-Garcia M, Sanchez-Perez AM, Nunez A, Ma S, Gundlach AL. 2012. Distribution and targets of the relaxin-3 innervation of the septal area in the rat. J Comp Neurol 520:1903-1939.

Olucha-Bordonau FE, Teruel V, Barcia-Gonzalez J, Ruiz-Torner A, Valverde-Navarro AA, MartinezSoriano F. 2003. Cytoarchitecture and efferent projections of the nucleus incertus of the rat. J Comp Neurol 464:62-97.

Paxinos G, Franklin KBJ. 2001. The Mouse Brain in Stereotaxic Coordinates. Academic Press, Sydney.

Peng Z, Zhang N, Wei W, Huang CS, Cetina Y, Otis TS, Houser CR. 2013. A reorganized GABAergic circuit in a model of epilepsy: evidence from optogenetic labeling and stimulation of somatostatin interneurons. J Neurosci 33:14392-14405.

Rawlins JN, Olton DS. 1982. The septo-hippocampal system and cognitive mapping. Behav Brain Res 5:331-358.

Reisel D, Bannerman DM, Schmitt WB, Deacon RM, Flint J, Borchardt T, Seeburg PH, Rawlins JN. 2002. Spatial memory dissociations in mice lacking GluR1. Nat Neurosci 5:868-873.

Ruediger S, Vittori C, Bednarek E, Genoud C, Strata P, Sacchetti B, Caroni P. 2011. Learning-related feedforward inhibitory connectivity growth required for memory precision. Nature 473:514-518.

Ryan PJ, Buchler E, Shabanpoor F, Hossain MA, Wade JD, Lawrence AJ, Gundlach AL. 2013. Central relaxin-3 receptor (RXFP3) activation decreases anxiety- and depressive-like behaviours in the rat. Behav Brain Res 244:142-151.

Ryding AD, Sharp MG, Mullins JJ. 2001. Conditional transgenic technologies. J Endocrinol 171:1-14.

Sanchez-Perez AM, Arnal-Vicente I, Santos FN, Pereira CW, ElMlili N, Sanjuan J, Ma S, Gundlach AL, Olucha-Bordonau FE. 2015. Septal projections to nucleus incertus in the rat: bidirectional pathways for modulation of hippocampal function. J Comp Neurol 523:565-588.

Sanderson DJ, Good MA, Seeburg PH, Sprengel R, Rawlins JN, Bannerman DM. 2008. The role of the GluR-A (GluR1) AMPA receptor subunit in learning and memory. Prog Brain Res 169:159178.

Scharfman HE, Myers CE. 2012. Hilar mossy cells of the dentate gyrus: a historical perspective. Front Neural Circuits 6:106.

Schiller D, Eichenbaum H, Buffalo EA, Davachi L, Foster DJ, Leutgeb S, Ranganath C. 2015. Memory and space: Towards an understanding of the cognitive map. J Neurosci 35:13904-13911.

Shabanpoor F, Hossain MA, Ryan PJ, Belgi A, Layfield S, Kocan M, Zhang S, Samuel CS, Gundlach AL, Bathgate RAD and others. 2012. Minimization of relaxin-3 leading to high affinity analogues with increased selectivity for relaxin-family peptide 3 receptor (RXFP3) over RXFP1. J Med Chem 55:1671-1681.

Smith CM, Ryan PJ, Hosken IT, Ma S, Gundlach AL. 2011. Relaxin-3 systems in the brain - the first 10 years. J Chem Neuroanat 42:262-275.

Smith CM, Shen PJ, Banerjee A, Bonaventure P, Ma S, Bathgate RA, Sutton SW, Gundlach AL. 2010. Distribution of relaxin-3 and RXFP3 within arousal, stress, affective, and cognitive circuits of mouse brain. J Comp Neurol 518:4016-4045.

Smith CM, Walker AW, Hosken IT, Chua BE, Zhang C, Haidar M, Gundlach AL. 2014. Relaxin3/RXFP3 networks: an emerging target for the treatment of depression and other neuropsychiatric diseases? Front Pharmacol 5:46.

Spiegel AM, Koh MT, Vogt NM, Rapp PR, Gallagher M. 2013. Hilar interneuron vulnerability distinguishes aged rats with memory impairment. J Comp Neurol 521:3508-3523.

Tanaka M, Iijima N, Miyamoto Y, Fukusumi S, Itoh Y, Ozawa H, Ibata Y. 2005. Neurons expressing relaxin 3/INSL 7 in the nucleus incertus respond to stress. Eur J Neurosci 21:1659-1670.

Toth K, Borhegyi Z, Freund TF. 1993. Postsynaptic targets of GABAergic hippocampal neurons in the medial septum-diagonal band of broca complex. J Neurosci 13:3712-3724.

Tuboly G, Vecsei L. 2013. Somatostatin and cognitive function in neurodegenerative disorders. Mini Rev Med Chem 13:34-46.

Vertes RP. 2005. Hippocampal theta rhythm: a tag for short-term memory. Hippocampus 15:923-935.

Vertes RP, Fortin WJ, Crane AM. 1999. Projections of the median raphe nucleus in the rat. J Comp Neurol 407:555-582. 
Vertes RP, Kocsis B. 1997. Brainstem-diencephalo-septohippocampal systems controlling the theta rhythm of the hippocampus. Neuroscience 81:893-926.

von Engelhardt J, Doganci B, Jensen V, Hvalby O, Gongrich C, Taylor A, Barkus C, Sanderson DJ, Rawlins JN, Seeburg PH and others. 2008. Contribution of hippocampal and extra-hippocampal NR2B-containing NMDA receptors to performance on spatial learning tasks. Neuron 60:846-860.

Vorhees CV, Williams MT. 2006. Morris water maze: procedures for assessing spatial and related forms of learning and memory. Nat Protoc 1:848-858.

Walker AW, Smith CM, Chua BE, Krstew EV, Zhang C, Gundlach AL, Lawrence AJ. 2015. Relaxin3 receptor (RXFP3) signalling mediates stress-related alcohol preference in mice. PLoS One 10:e0122504.

Watanabe Y, Tsujimura A, Takao K, Nishi K, Ito Y, Yasuhara Y, Nakatomi Y, Yokoyama C, Fukui K, Miyakawa T, Tanaka M. 2011. Relaxin-3-deficient mice showed slight alteration in anxietyrelated behavior. Front Behav Neurosci 5:50.

Xu X, Roby KD, Callaway EM. 2010. Immunochemical characterization of inhibitory mouse cortical neurons: three chemically distinct classes of inhibitory cells. J Comp Neurol 518:389-404.

Yamazaki M, Matsuoka N, Maeda N, Ohkubo Y, Yamaguchi I. 1996. FK960 N-(4-acetyl-1piperazinyl)-p-fluorobenzamide monohydrate ameliorates the memory deficits in rats through a novel mechanism of action. J Pharmacol Exp Ther 279:1157-1173.

Zappone CA, Sloviter RS. 2001. Commissurally projecting inhibitory interneurons of the rat hippocampal dentate gyrus: a colocalization study of neuronal markers and the retrograde tracer Fluoro-gold. J Comp Neurol 441:324-344.

Zhang C, Chua BE, Yang A, Shabanpoor F, Hossain MA, Wade JD, Rosengren KJ, Smith CM, Gundlach AL. 2015. Central relaxin-3 receptor (RXFP3) activation reduces elevated, but not basal, anxiety-like behaviour in C57BL/6J mice. Behav Brain Res 292:125-132.

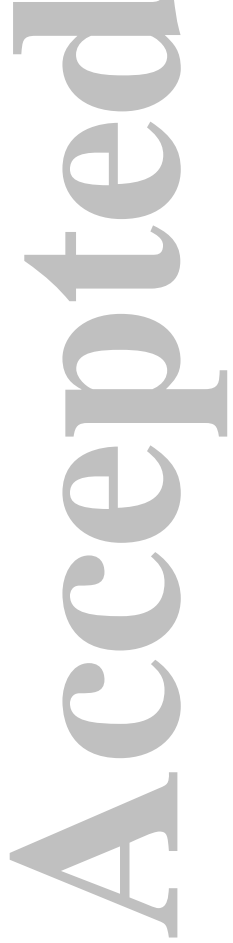




\section{Figure Legends}

FIGURE 1. RXFP3 mRNA in the mouse dorsal hippocampus.

Representative dark-field photomicrographs of emulsion autoradiographic analysis of RXFP3 mRNA expression in the hippocampus. (A) Silver grains for RXFP3 mRNA were detected in the DG hilus (B), the pyramidal layer and stratum oriens of the CA1 (C) and the radiatum, pyramidal layer and stratum oriens of the CA3 (D). Boxed areas in (A) indicate the areas illustrated in magnified images in (B, C and D).

FIGURE 2. RLN3-positive nerve fibres and terminals in the mouse dorsal hippocampus.

Mosaic confocal image (20× magnification represented as $z$-stack maximum projections, $1 \mu \mathrm{m}$ intervals) of mouse dorsal hippocampus illustrating RLN3-positive nerve fibres and terminals (A). Nerve fibres and terminals containing RLN3-IR were detected in the DG hilus (B), the pyramidal layer and stratum oriens of the CA1 (C) and the radiatum, pyramidal layer and stratum oriens on the CA3 (D). Boxed areas in (A) indicate the areas illustrated in magnified images (63x maximum projections Z-stacks, $0.1 \mu \mathrm{m}$ intervals) (B, C, D). Scale bars, $200 \mu \mathrm{m}$ (A) and $20 \mu \mathrm{m}$ (B, C and D).

FIGURE 3. Comparative distribution in mouse dorsal hippocampus of RXFP3 mRNA and mRNAs encoding peptide and protein markers of hippocampal interneurons.

(A) Distribution of RXFP3 mRNA in adult mouse hippocampus with abundant expression detected in neurons located in CA1 stratum oriens, across the CA3 region and within the hilus of the dentate gyrus (DG) with higher magnification views of $\mathrm{CA} 3$ and DG (boxed areas) provided $\left(\mathbf{A}^{\prime}, \mathbf{A}^{\prime \prime}\right)$. The comparative distribution of GAD67 (B), SST (C), PV (D), and CR (E) mRNAs illustrate the strong similarity between the distribution of RXFP3 mRNA positive neurons and some of the GAD67, SST, $\mathrm{PV}$ and CR mRNA positive neurons in the CA1 stratum oriens, CA3 region and hilus, suggesting that RXFP3 is expressed by a population of GABA interneurons (or projection neurons) in these areas. Images adapted from the Allen Brain Institute Gene Expression Atlas <www.brain-map.org>.

FIGURE 4. Comparative distribution of RLN3-immunoreactive nerve fibres and neurons positive for amino acid, peptide or protein markers of hippocampal interneurons in dorsal hippocampus of adult mouse.

Mosaic confocal images (20× magnification represented as z-stack maximum projections, $1 \mu \mathrm{m}$ intervals) of mouse DG illustrating (A) RLN3 (red), SST (green) and PV (blue) immunoreactivity, (B) RLN3 (red) and GABA (green) immunoreactivity, and (C) RLN3 (red) and CR (green) immunoreactivity. Boxed areas in A-C are further illustrated (63× magnification z-stacks, $0.1 \mu \mathrm{m}$ intervals) and represented as three-dimensional orthogonal maximum projections orientated in 3 planes $(y / x, x / z$ and $y / z)\left(\mathbf{A}^{\prime}, \mathbf{B}^{\prime}, \mathbf{C}^{\prime}\right)$. Dotted lines in these panels indicate appositions of RLN3positive elements with hippocampal neurons in the $y / x, x / z$ and $y / z$ planes. Scale bars represent 100 $\mu \mathrm{m}(\mathbf{A}, \mathbf{B}, \mathbf{C})$ and $20 \mu \mathrm{m}\left(\mathbf{A}^{\prime}, \mathbf{B}^{\prime}, \mathbf{C}^{\prime}\right)$. 
FIGURE 5. Comparative distribution of eGFP, Cre-recombinase and somatostatin (SST) in hilar neurons of dorsal hippocampus in mice injected with the AAV $V^{(1 / 2)}$-Cre-IRES-eGFP viral vector.

Bilateral injections of $\mathrm{AAV}^{(1 / 2)}$-Cre-IRES-eGFP into the dentate gyrus (DG) of floxed-RXFP3 mice resulted in expression of eGFP (A) and Cre-immunoreactivity (B) in neurons of the DG hilus. Creimmunoreactivity and endogenous eGFP immunofluorescence were consistently observed in SSTimmunoreactive neurons in the region (C, D), consistent with the likely deletion of any RXFP3 expression from these neurons. In the higher magnification images (inserts), arrowheads indicate some of many neurons in which eGFP, Cre and SST are co-localized. Scale bars, $100 \mu \mathrm{m}$ (A-D) and $20 \mu \mathrm{m}$ (insets).

FIGURE 6. Effect of an $A A V^{(1 / 2)}$-Cre-IRES-eGFP or an $A A V^{(1 / 2)}-e G F P$ viral vector injection into the dorsal dentate gyrus hilus of floxed-RXFP3 mice on levels of RXFP3 $m R N A$ in the target and CA3 regions, and a schematic illustration of the virus distribution observed.

Representative dark-field photomicrographs of nuclear emulsion autoradiographic images of the distribution of RXFP3 mRNA in DG hilus of floxed RXFP3 mice labeled by an $\left[{ }^{35} \mathrm{~S}\right]$-riboprobe (Lenglos et al., 2014) following bilateral injections of either (A) AAV ${ }^{(1 / 2)}-\mathrm{eGFP}$, or (B) $\mathrm{AAV}^{(1 / 2)}$-CreIRES-eGFP. A significant reduction in relative RXFP3 mRNA levels was observed after bilateral $A A V^{(1 / 2)}$-Cre-IRES-eGFP injections into the DG hilus, relative to bilateral $\mathrm{AAV}^{(1 / 2)}$-eGFP (control) injections in (C) hilus and (D) CA3 (unpaired t-test, ${ }^{* *} p<0.01, n=3-5$ mice per group). Data are expressed as mean \pm SEM. (E) Schematic representation of viral spread observed within the DG of treated mice. The distribution of virus and Cre recombinase was similar on both sides of the hippocampus in all of the mice included in the final behavioural analysis. (Coronal brain mages adapted from a stereotaxic mouse brain atlas (Paxinos and Franklin 2001)).

FIGURE 7. Effect of RXFP3 deletion in the dentate gyrus hilus of adult floxed-RXFP3 mice on subsequent spatial reference memory in an appetitive T-maze.

An AAV ${ }^{(1 / 2)}$-Cre-IRES-eGFP or an $\mathrm{AAV}^{(1 / 2)}$-eGFP (control) viral vector was injected bilaterally into the dentate gyrus (DG) of groups of floxed-RXFP3 mice and their spatial memory was tested after a 3week recovery period. (A) During acquisition training, mice with RXFP3 deleted from DG hilus made significantly less correct choices than control mice on day 1-3 of testing in a hippocampus-dependent spatial reference memory task - an appetitive T-maze. RXFP3 deleted and control mice performed similarly during reversal training (2-way repeated measures ANOVA, Bonferroni post-hoc analysis, * $p<0.05$ ). (B) Mice with RXFP3 deleted from DG hilus took significantly more days of training than control mice to meet criteria during acquisition (Mann-Whitney U-test, ${ }^{*} p<0.05$ ). No treatment differences were observed during reversal training. Data are expressed as mean $\pm \mathrm{SEM}, n=12-13$ mice per group. 
FIGURE 8. Effect of RXFP3 deletion in the dentate gyrus hilus of adult floxed-RXFP3 mice on subsequent performance in a spontaneous alternation task in a Y-maze.

An $\mathrm{AAV}^{(1 / 2)}$-Cre-IRES-eGFP or an $\mathrm{AAV}^{(1 / 2)}$-eGFP (control) viral vector was injected bilaterally into the dentate gyrus (DG) of groups of floxed-RXFP3 mice and their performance in a spontaneous alternation task in a Y-maze was tested after a 3-week recovery period. Mice with RXFP3 deleted from DG hilus displayed a significant reduction in percent alternation score (PAS) in the first min of a spontaneous alternation task (SAT) in the Y-maze, relative to control mice. No treatment differences in PAS were observed during the $2^{\text {nd }}$ or $3^{\text {rd }}$ min bins of the test (Unpaired t-test, *** $p<0.001, n=12$

-13 mice per group). Horizontal dotted line indicates $50 \%$ chance level.

TIGURE

FIGURE 9. Effect of RXFP3 deletion in the dentate gyrus hilus of adult floxed-RXFP3 mice on spatial learning and long-term reference memory in a Morris water maze (MWM) test.

An AAV ${ }^{(1 / 2)}$-Cre-IRES-eGFP or an $\mathrm{AAV}^{(1 / 2)-}$ eGFP (control) viral vector was injected bilaterally into the dentate gyrus (DG) of groups of floxed-RXFP3 mice and their performance in a Morris water maze (MWM) test was tested after a 3-week recovery period. (A) Mice with RXFP3 deleted from DG hilus and matched control mice displayed normal spatial learning in the MWM. (B) On the probe day, both groups spent significantly more time in the target quadrant relative to other quadrants (one-way ANOVA, Bonferroni post-hoc analysis, ${ }^{*} p<0.05,{ }^{* * * *} p<0.0001, n=12-13$ mice per group). Data are expressed as mean \pm SEM. Horizontal dotted line indicate $25 \%$ chance level. Abbreviations: $\mathrm{T}$, target quadrant (SW), A, adjacent quadrants (NW, SE) and O opposite quadrant (NE).

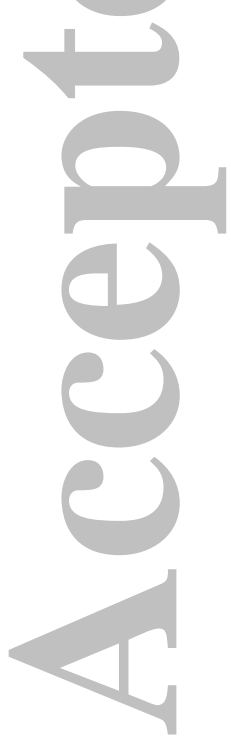

John Wirey \& Sons

This article is protected by copyright. All rights reserved. 


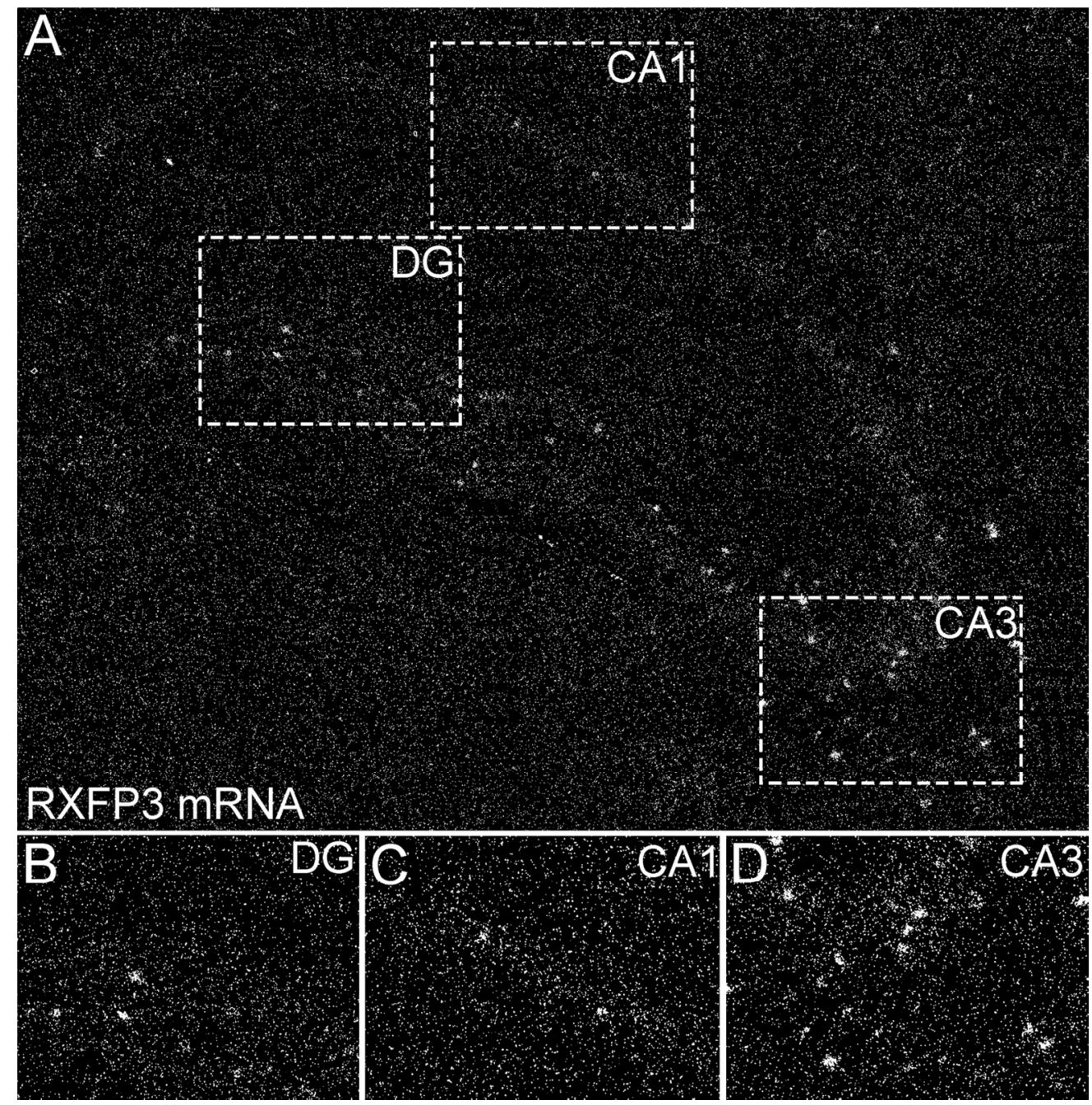

FIGURE 1. RXFP3 mRNA in the mouse dorsal hippocampus.

Representative dark-field photomicrographs of emulsion autoradiographic analysis of RXFP3 mRNA expression in the hippocampus. (A) Silver grains for RXFP3 mRNA were detected in the DG hilus (B), the pyramidal layer and stratum oriens of the CA1 (C) and the radiatum, pyramidal layer and stratum oriens of the CA3 (D). Boxed areas in $(A)$ indicate the areas illustrated in magnified images in $(B, C$ and $D)$.

$124 \times 126 \mathrm{~mm}(300 \times 300 \mathrm{DPI})$ 


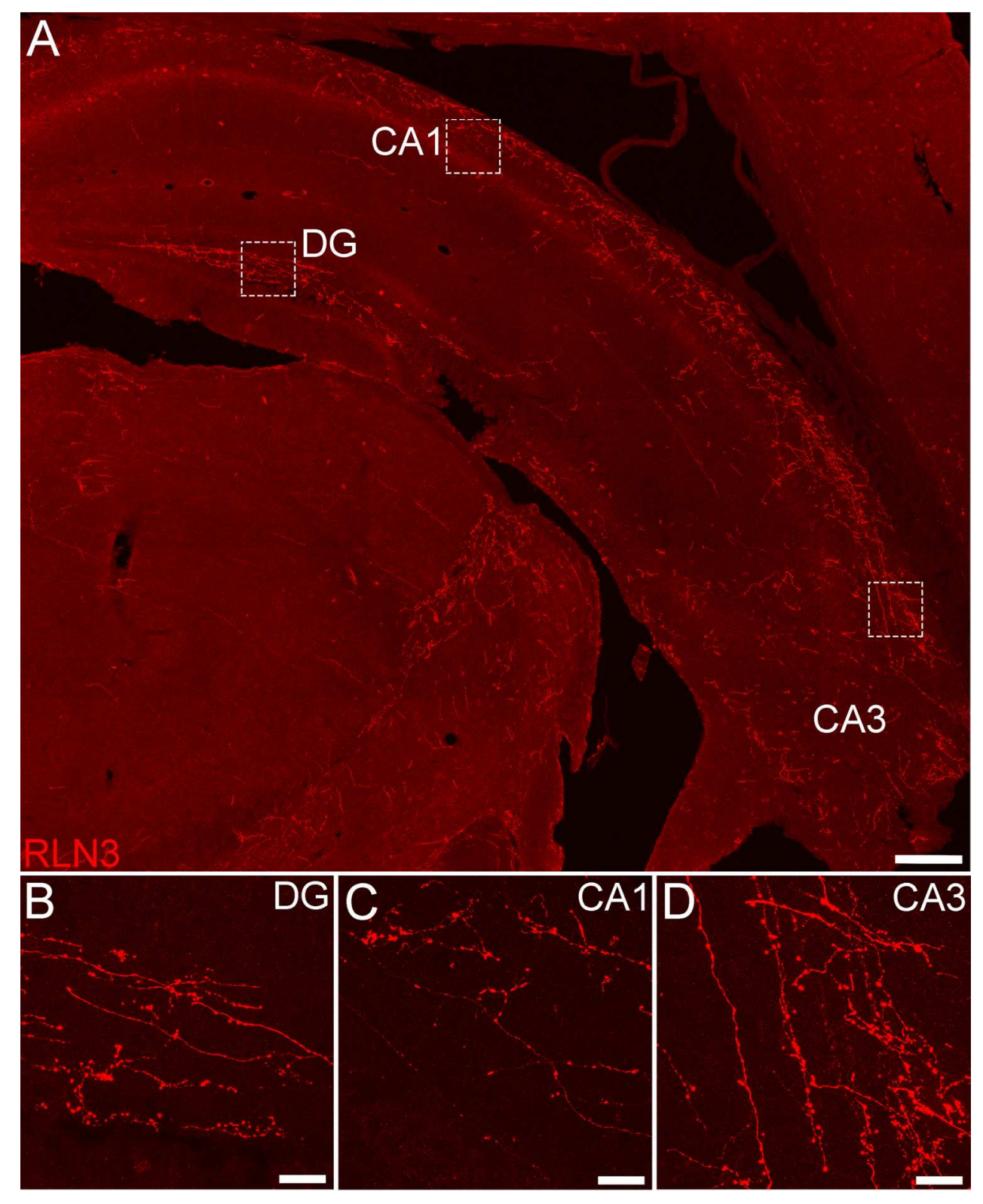

FIGURE 2. RLN3-positive nerve fibres and terminals in the mouse dorsal hippocampus.

Mosaic confocal image ( $20 \times$ magnification represented as $z$-stack maximum projections, $1 \mu \mathrm{m}$ intervals) of mouse dorsal hippocampus illustrating RLN3-positive nerve fibres and terminals (A). Nerve fibres and terminals containing RLN3-IR were detected in the DG hilus (B), the pyramidal layer and stratum oriens of the CA1 (C) and the radiatum, pyramidal layer and stratum oriens on the CA3 (D). Boxed areas in (A) indicate the areas illustrated in magnified images (63x maximum projections $z$-stacks, $0.1 \mu \mathrm{m}$ intervals) (B, C, D). Scale bars, $200 \mu \mathrm{m}(A)$ and $20 \mu \mathrm{m}$ (B, C and D).

$$
151 \times 187 \mathrm{~mm}(300 \times 300 \text { DPI) }
$$




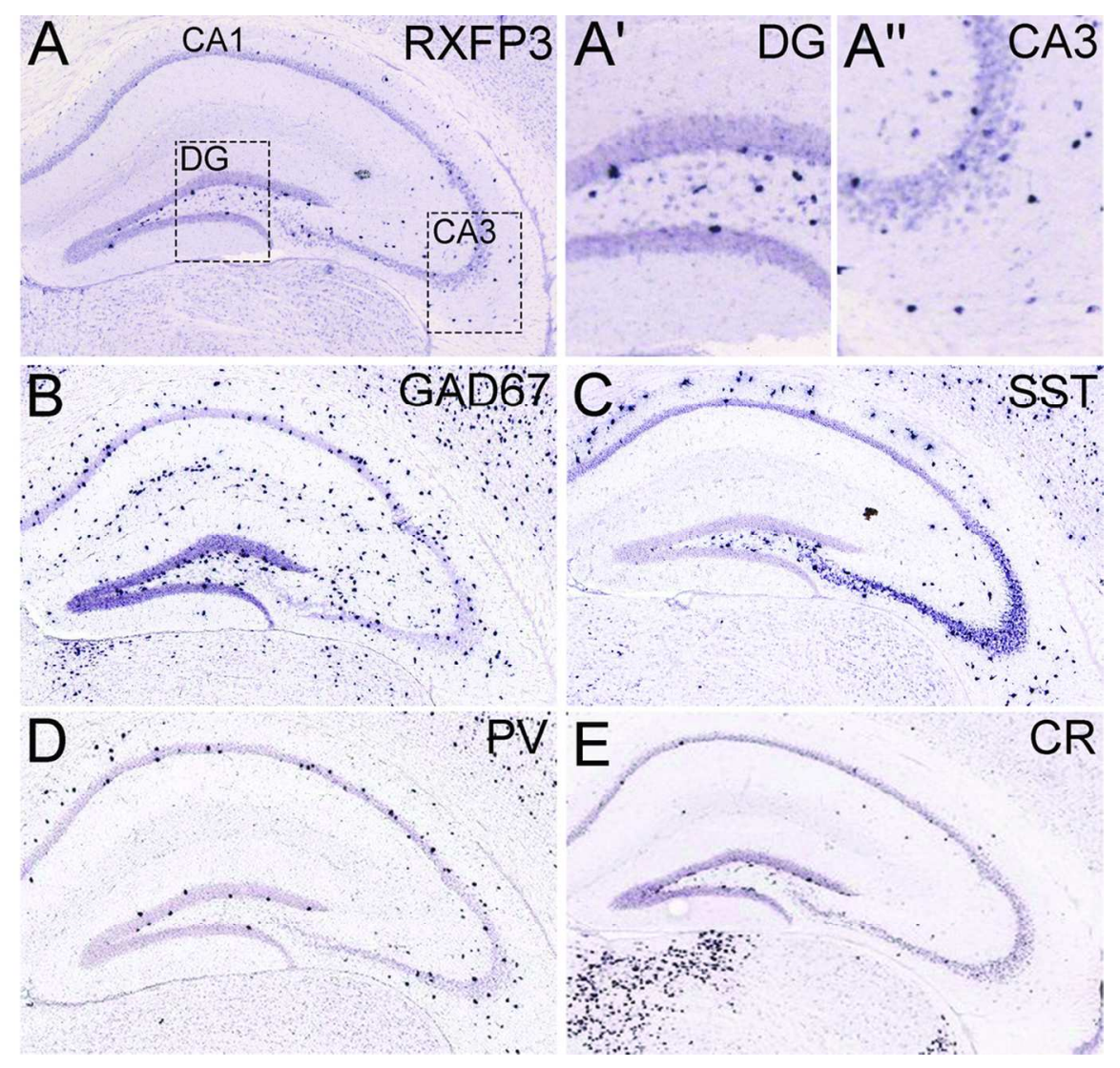

FIGURE 3. Comparative distribution in mouse dorsal hippocampus of RXFP3 mRNA and mRNAs encoding peptide and protein markers of hippocampal interneurons.

(A) Distribution of RXFP3 mRNA in adult mouse hippocampus with abundant expression detected in neurons located in CA1 stratum oriens, across the CA3 region and within the hilus of the dentate gyrus (DG) with higher magnification views of CA3 and DG (boxed areas) provided $\left(A^{\prime}, A^{\prime \prime}\right)$. The comparative distribution of GAD67 (B), SST (C), PV (D), and CR (E) mRNAs illustrate the strong similarity between the distribution of RXFP3 mRNA positive neurons and some of the GAD67, SST, PV and CR mRNA positive neurons in the CA1 stratum oriens, CA3 region and hilus, suggesting that RXFP3 is expressed by a population of GABA interneurons (or projection neurons) in these areas. Images adapted from the Allen Brain Institute Gene Expression Atlas <www.brain-map.org>.

$109 \times 91 \mathrm{~mm}(300 \times 300 \mathrm{DPI})$

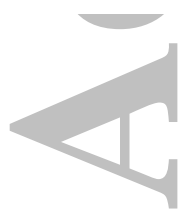



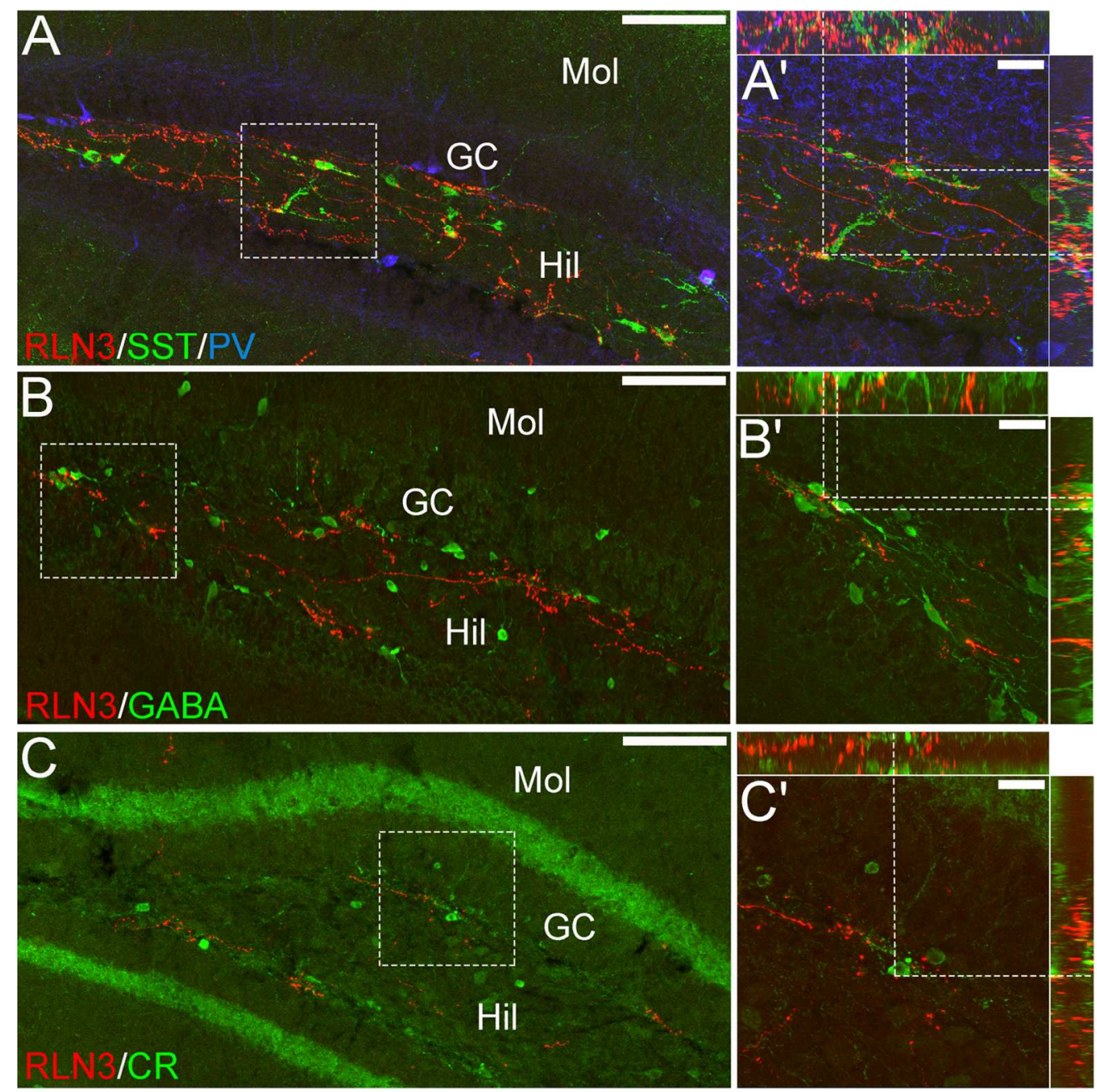

FIGURE 4. Comparative distribution of RLN3-immunoreactive nerve fibres and neurons positive for amino acid, peptide or protein markers of hippocampal interneurons in dorsal hippocampus of adult mouse.

Mosaic confocal images ( $20 \times$ magnification represented as z-stack maximum projections, $1 \mu \mathrm{m}$ intervals) of mouse DG illustrating (A) RLN3 (red), SST (green) and PV (blue) immunoreactivity, (B) RLN3 (red) and GABA (green) immunoreactivity, and (C) RLN3 (red) and CR (green) immunoreactivity. Boxed areas in A-C are further illustrated (63× magnification z-stacks, $0.1 \mu \mathrm{m}$ intervals) and represented as three-dimensional orthogonal maximum projections orientated in 3 planes $(y / x, x / z$ and $y / z)\left(A^{\prime}, B^{\prime}, C^{\prime}\right)$. Dotted lines in these panels indicate appositions of RLN3-positive elements with hippocampal neurons in the $y / x, x / z$ and $y / z$ planes. Scale bars represent $100 \mu \mathrm{m}(\mathrm{A}, \mathrm{B}, \mathrm{C})$ and $20 \mu \mathrm{m}\left(\mathrm{A}^{\prime}, \mathrm{B}^{\prime}, \mathrm{C}^{\prime}\right)$.

$126 \times 126 \mathrm{~mm}(300 \times 300 \mathrm{DPI})$ 


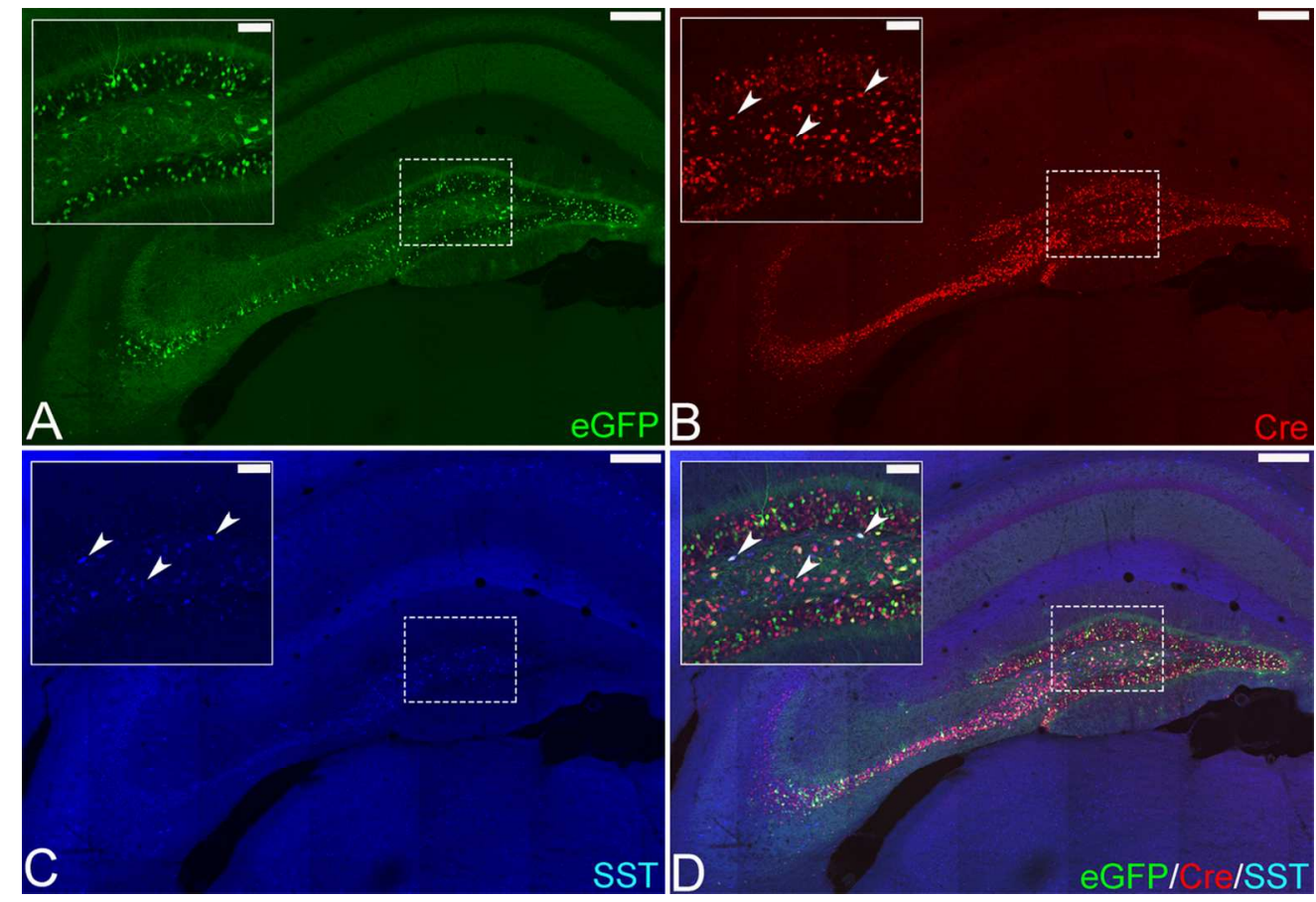

FIGURE 5. Comparative distribution of eGFP, Cre-recombinase and somatostatin (SST) in hilar neurons of dorsal hippocampus in mice injected with the AAV(1/2)-Cre-IRES-eGFP viral vector.

Bilateral injections of AAV(1/2)-Cre-IRES-eGFP into the dentate gyrus (DG) of floxed-RXFP3 mice resulted in expression of eGFP (A) and Cre-immunoreactivity (B) in neurons of the DG hilus. Cre-immunoreactivity and endogenous eGFP immunofluorescence were consistently observed in SST-immunoreactive neurons in the region $(C, D)$, consistent with the likely deletion of any RXFP3 expression from these neurons. In the higher magnification images (inserts), arrowheads indicate some of many neurons in which eGFP, Cre and SST are co-localized. Scale bars, $100 \mu \mathrm{m}$ (A-D) and $20 \mu \mathrm{m}$ (insets).

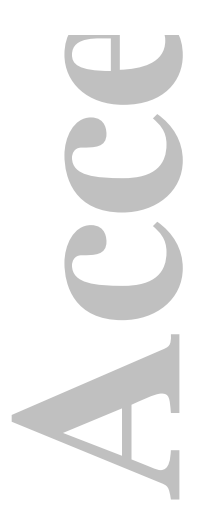

$109 \times 75 \mathrm{~mm}(300 \times 300$ DPI $)$ 

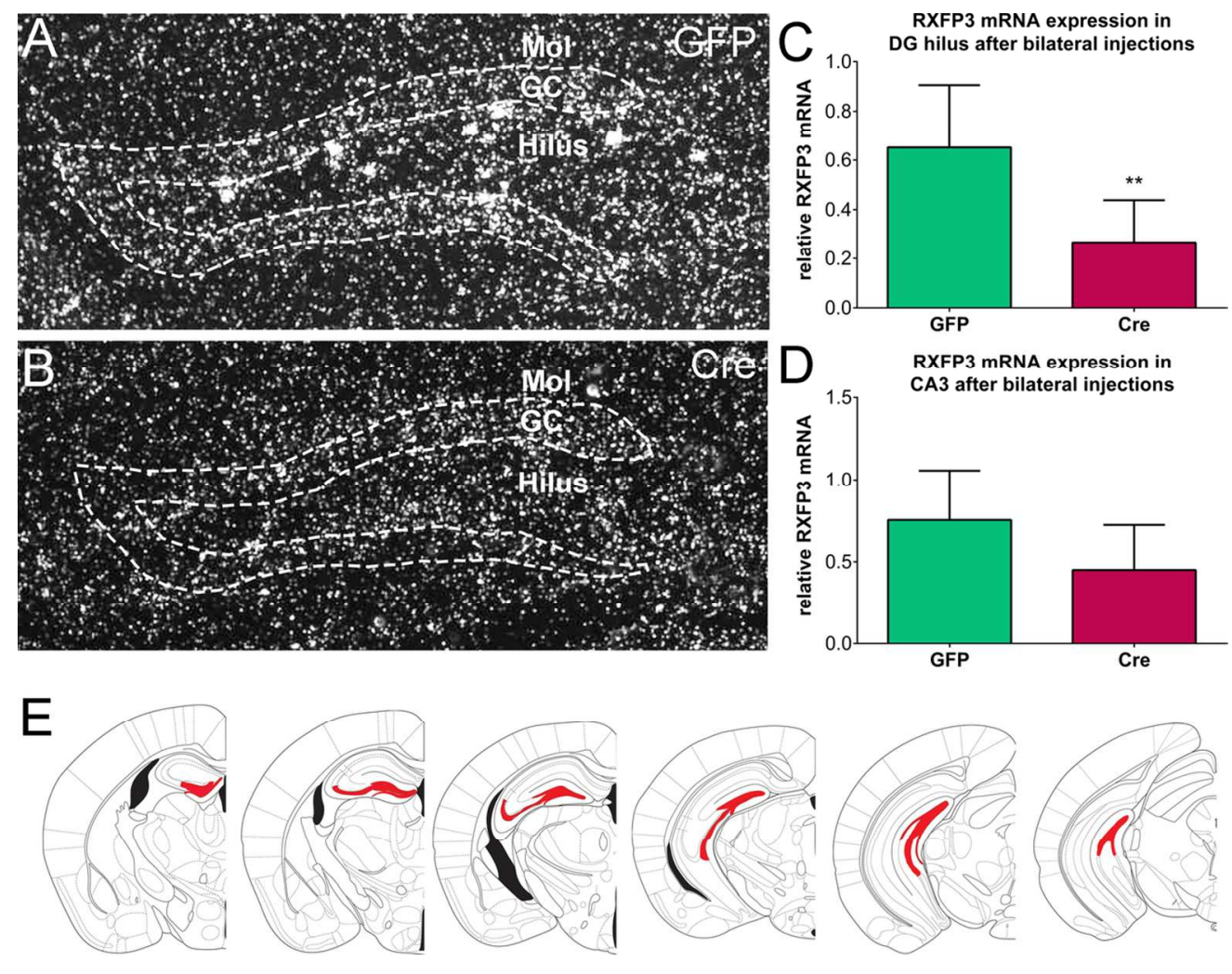

FIGURE 6. Effect of an AAV(1/2)-Cre-IRES-eGFP or an AAV(1/2)-eGFP viral vector injection into the dorsal dentate gyrus hilus of floxed-RXFP3 mice on levels of RXFP3 mRNA in the target and CA3 regions, and a schematic illustration of the virus distribution observed.

Representative dark-field photomicrographs of nuclear emulsion autoradiographic images of the distribution of RXFP3 mRNA in DG hilus of floxed RXFP3 mice labeled by an [35S]-riboprobe (Lenglos et al., 2014) following bilateral injections of either (A) AAV(1/2)-eGFP, or (B) AAV(1/2)-Cre-IRES-eGFP. A significant reduction in relative RXFP3 mRNA levels was observed after bilateral AAV(1/2)-Cre-IRES-eGFP injections into the DG hilus, relative to bilateral AAV(1/2)-eGFP (control) injections in (C) hilus and (D) CA3 (unpaired t-test, $* * \mathrm{p}<0.01, \mathrm{n}=3-5$ mice per group). Data are expressed as mean \pm SEM. (E) Schematic representation of viral spread observed within the DG of treated mice. The distribution of virus and Cre recombinase was similar on both sides of the hippocampus in all of the mice included in the final behavioural analysis. (Coronal brain mages adapted from a stereotaxic mouse brain atlas (Paxinos and Franklin 2001)).

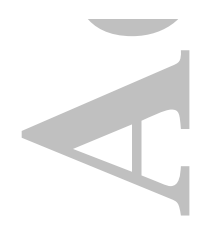

$112 \times 87 \mathrm{~mm}(300 \times 300 \mathrm{DPI})$ 

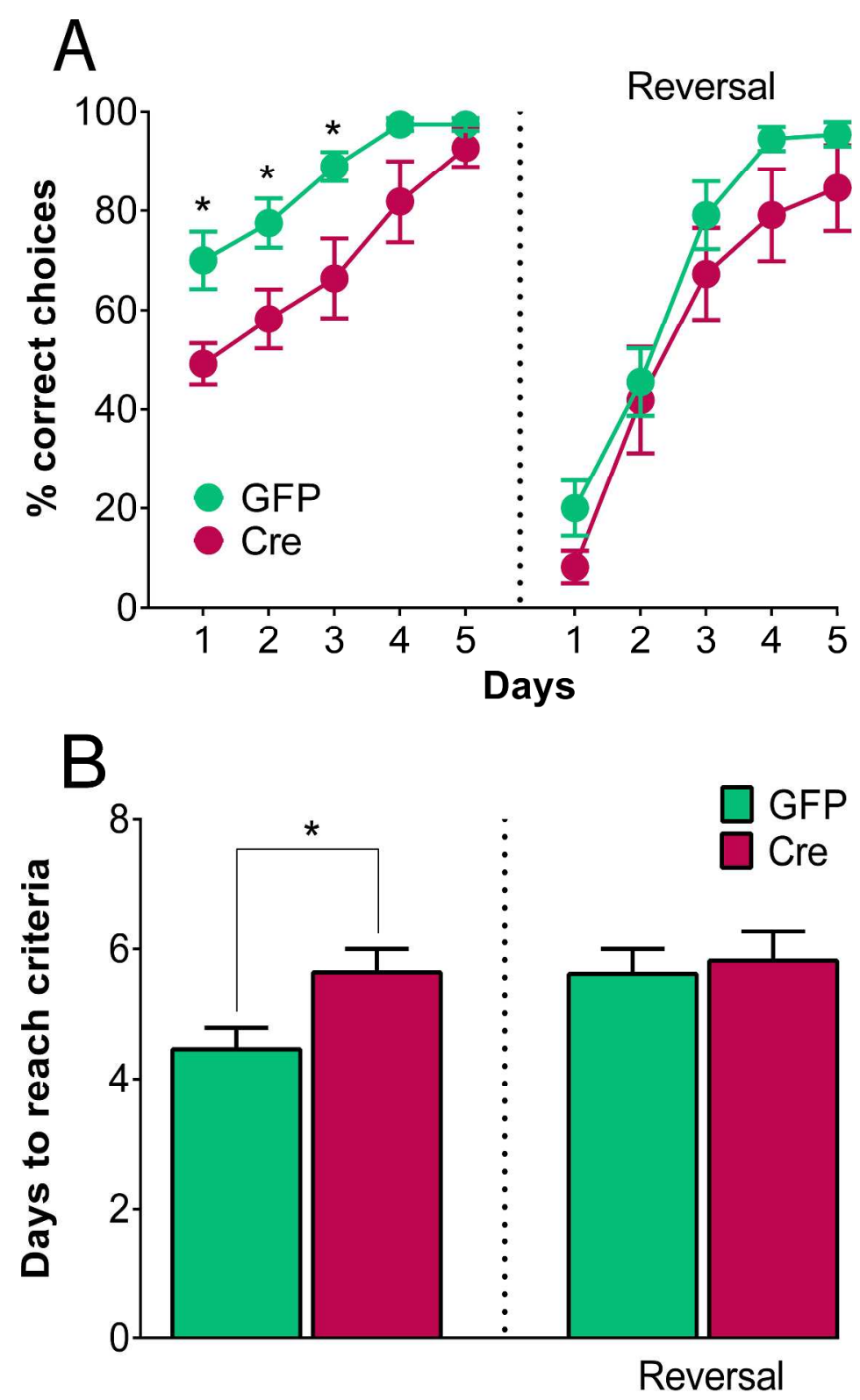

FIGURE 7. Effect of RXFP3 deletion in the dentate gyrus hilus of adult floxed-RXFP3 mice on subsequent spatial reference memory in an appetitive T-maze.

An AAV(1/2)-Cre-IRES-eGFP or an AAV(1/2)-eGFP (control) viral vector was injected bilaterally into the dentate gyrus (DG) of groups of floxed-RXFP3 mice and their spatial memory was tested after a 3-week recovery period. (A) During acquisition training, mice with RXFP3 deleted from DG hilus made significantly less correct choices than control mice on day 1-3 of testing in a hippocampus-dependent spatial reference memory task - an appetitive T-maze. RXFP3 deleted and control mice performed similarly during reversal training (2-way repeated measures ANOVA, Bonferroni post-hoc analysis, * $p<0.05$ ). (B) Mice with RXFP3 deleted from DG hilus took significantly more days of training than control mice to meet criteria during acquisition (Mann-Whitney U-test, $* p<0.05$ ). No treatment differences were observed during reversal training. Data are expressed as mean \pm SEM, $\mathrm{n}=12-13$ mice per group.

$114 \times 189 \mathrm{~mm}(600 \times 600 \mathrm{DPI})$ 

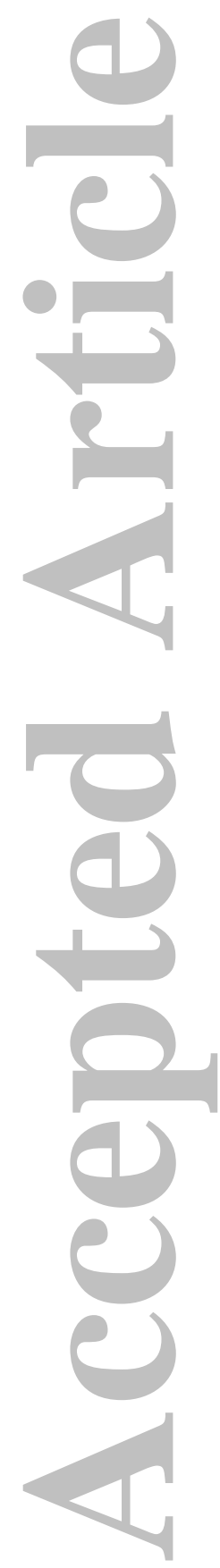

John Wiley \& Sons

This article is protected by copyright. All rights reserved. 


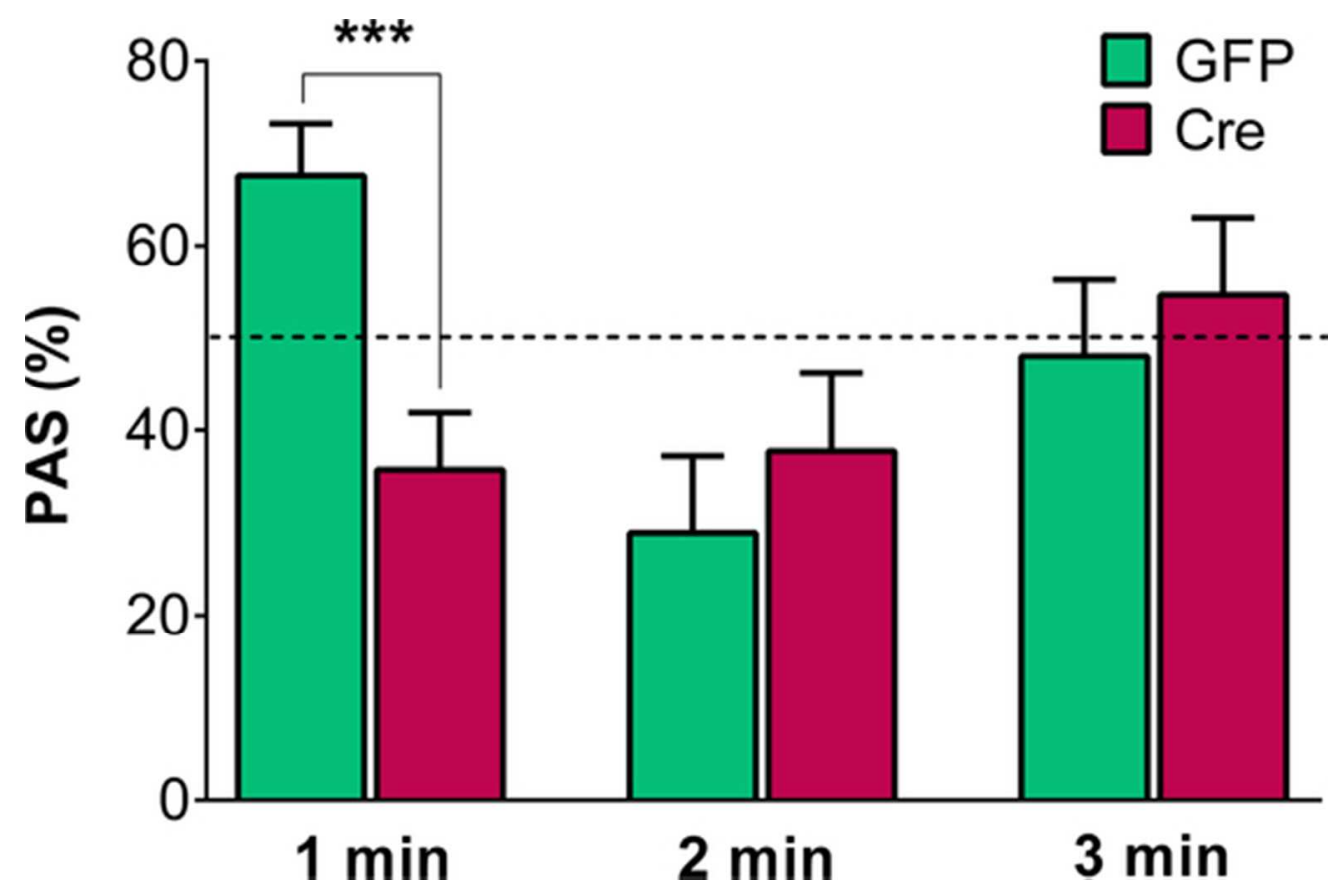

FIGURE 8. Effect of RXFP3 deletion in the dentate gyrus hilus of adult floxed-RXFP3 mice on subsequent performance in a spontaneous alternation task in a Y-maze.

An AAV(1/2)-Cre-IRES-eGFP or an AAV(1/2)-eGFP (control) viral vector was injected bilaterally into the dentate gyrus (DG) of groups of floxed-RXFP3 mice and their performance in a spontaneous alternation task in a Y-maze was tested after a 3-week recovery period. Mice with RXFP3 deleted from DG hilus displayed a significant reduction in percent alternation score (PAS) in the first min of a spontaneous alternation task (SAT) in the Y-maze, relative to control mice. No treatment differences in PAS were observed during the 2nd or 3rd min bins of the test (Unpaired t-test, $* * * \mathrm{p}<0.001, \mathrm{n}=12-13$ mice per group). Horizontal dotted line indicates $50 \%$ chance level.

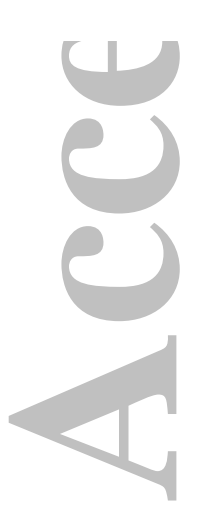

$47 \times 31 \mathrm{~mm}(300 \times 300$ DPI $)$ 

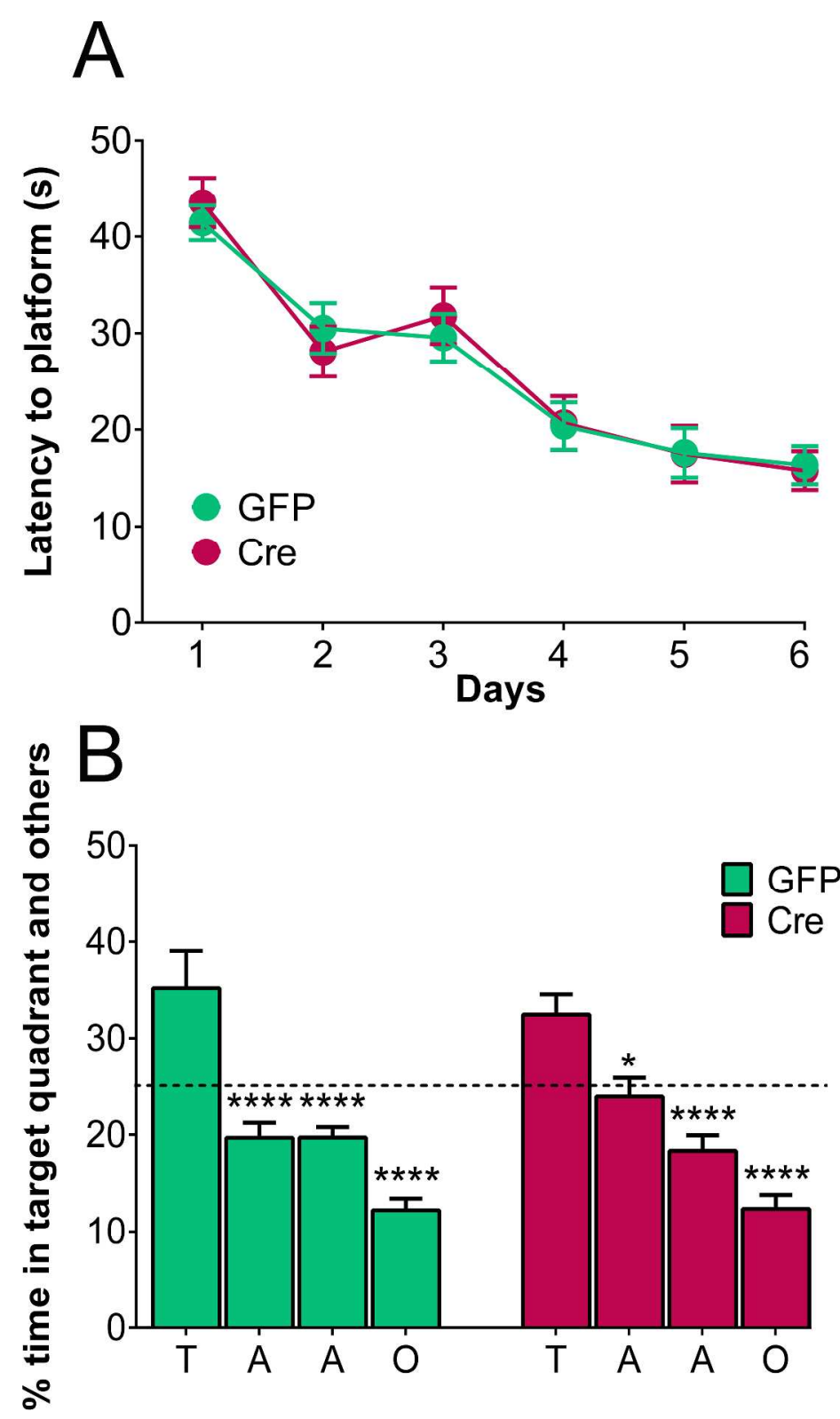

FIGURE 9. Effect of RXFP3 deletion in the dentate gyrus hilus of adult floxed-RXFP3 mice on spatial learning and long-term reference memory in a Morris water maze (MWM) test.

An AAV(1/2)-Cre-IRES-eGFP or an AAV(1/2)-eGFP (control) viral vector was injected bilaterally into the dentate gyrus (DG) of groups of floxed-RXFP3 mice and their performance in a Morris water maze (MWM) test was tested after a 3-week recovery period. (A) Mice with RXFP3 deleted from DG hilus and matched control mice displayed normal spatial learning in the MWM. (B) On the probe day, both groups spent significantly more time in the target quadrant relative to other quadrants (one-way ANOVA, Bonferroni posthoc analysis, $* \mathrm{p}<0.05, * * * * \mathrm{p}<0.0001, \mathrm{n}=12-13$ mice per group). Data are expressed as mean \pm SEM. Horizontal dotted line indicate $25 \%$ chance level. Abbreviations: T, target quadrant (SW), A, adjacent quadrants (NW, SE) and O opposite quadrant (NE).

$$
113 \times 191 \mathrm{~mm}(600 \times 600 \mathrm{DPI})
$$



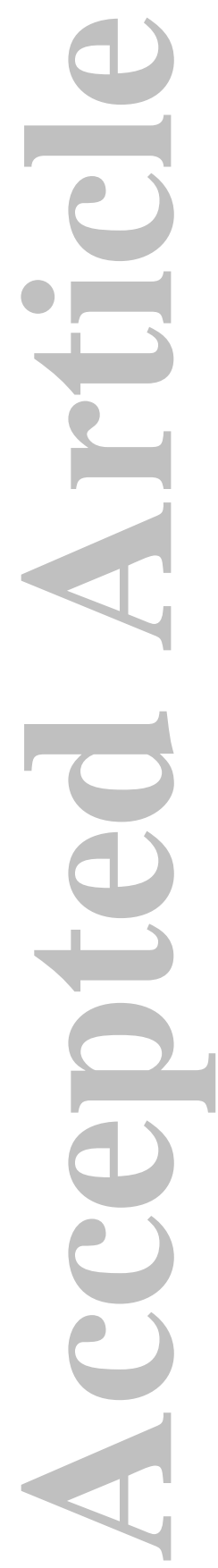

John Wiley \& Sons

This article is protected by copyright. All rights reserved. 


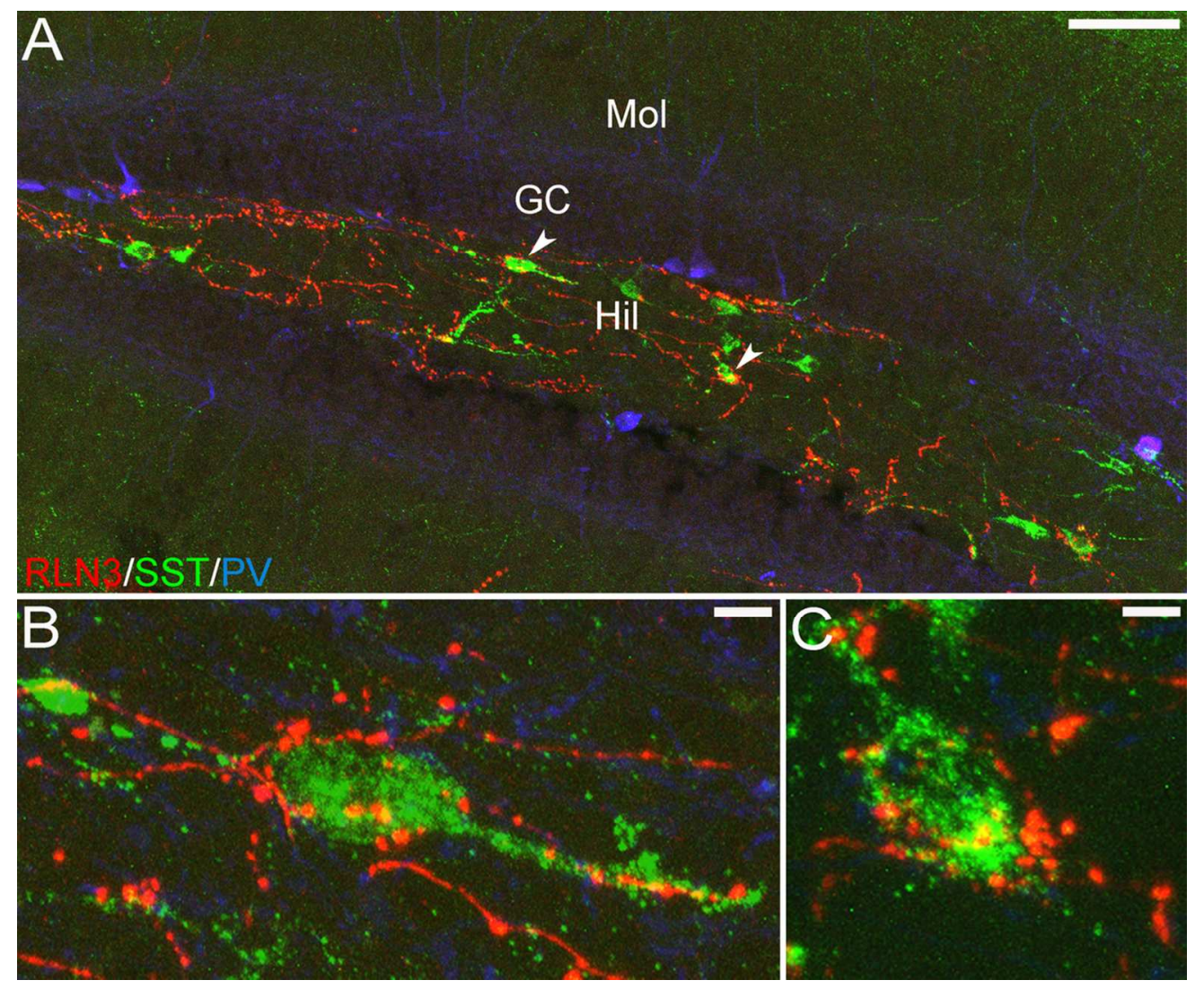

FIGURE S1. Comparative distribution of RLN3-immunoreactive nerve fibres and hippocampal neurons immunoreactive for somatostatin (SST) and parvalbumin (PV) in the dorsal DG hilus of adult mouse hippocampus.

Mosaic confocal images ( $20 \times$ magnification represented as z-stack maximum projections, $1 \mu \mathrm{m}$ intervals) of mouse DG (reproduced from Figure 4), illustrating (A) RLN3 (red), SST (green) and PV (blue) immunoreactivity. Further details of the putative interactions between RLN3 inputs and SST neurons were recorded in this section. The DG hilar SST-positive neurons indicated by arrowheads in A, are illustrated at higher resolution in (B) and (C). There are several points of close apposition between the RLN3 fibres/boutons and the soma and proximal/distal processes of the SST neurons (yellow). Scale bars, $100 \mu \mathrm{m}$ (A) and $20 \mu \mathrm{m}(B, C)$.

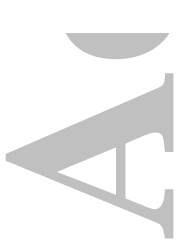

$105 \times 87 \mathrm{~mm}(300 \times 300$ DPI $)$ 


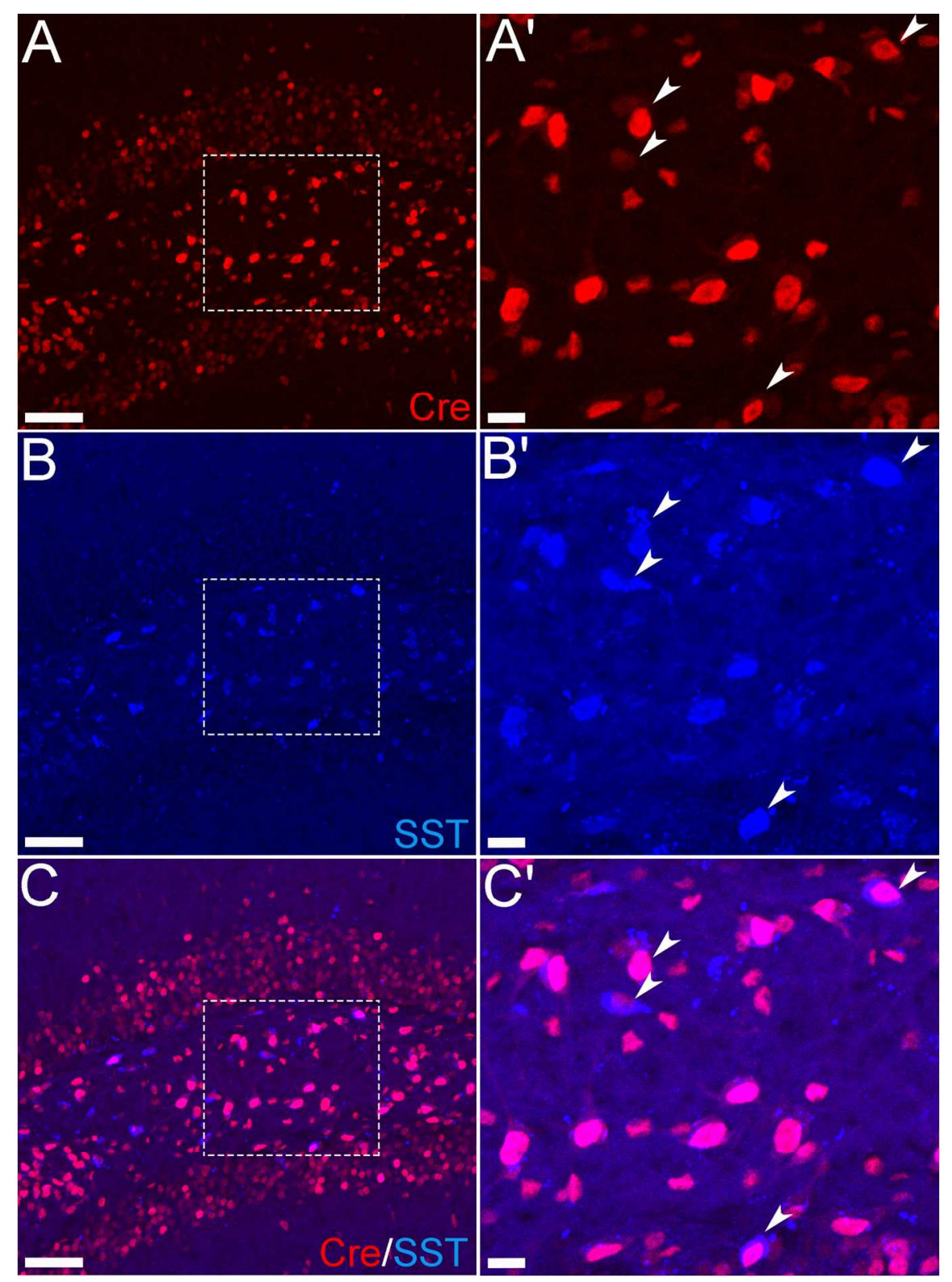

FIGURE S2. Comparative distribution of Cre-recombinase and somatostatin (SST) in DG hilar neurons of dorsal hippocampus in mice injected with the AAV(1/2)-Cre-IRES-eGFP viral vector.

Bilateral injections of AAV(1/2)-Cre-IRES-eGFP into the DG of floxed-RXFP3 mice resulted in expression of Cre-immunoreactivity (red) $\left(A, A^{\prime}\right)$ in SST neurons (blue) $\left(B, B^{\prime}\right)$ of the DG hilus. Cre-immunoreactivity (pink) was consistently observed in the nuclei of SST-immunoreactive neurons in the region $\left(C, C^{\prime}\right)$, consistent with the deletion of RXFP3 expression from these neurons. In the higher magnification images of the boxed areas $\left(A^{\prime}, B^{\prime}, C^{\prime}\right)$, arrowheads indicate examples of neurons in which Cre and SST are colocalized. Scale bars, $100 \mu \mathrm{m}(A-C)$ and $20 \mu \mathrm{m}\left(A^{\prime}-C^{\prime}\right)$.

$137 \times 187 \mathrm{~mm}(300 \times 300$ DPI) 


\section{University Library}

\section{- M M N E R VA A gateway to Melbourne's research publications}

Minerva Access is the Institutional Repository of The University of Melbourne

Author/s:

Haidar, M;Guevremont, G;Zhang, C;Bathgate, RAD;Timofeeva, E;Smith, CM;Gundlach, AL

Title:

Relaxin-3 Inputs Target Hippocampal Interneurons and Deletion of Hilar Relaxin-3 Receptors in "Floxed-RXFP3" Mice Impairs Spatial Memory

Date:

2017-05-01

Citation:

Haidar, M., Guevremont, G., Zhang, C., Bathgate, R. A. D., Timofeeva, E., Smith, C. M. \& Gundlach, A. L. (2017). Relaxin-3 Inputs Target Hippocampal Interneurons and Deletion of Hilar Relaxin-3 Receptors in "Floxed-RXFP3" Mice Impairs Spatial Memory. HIPPOCAMPUS, 27 (5), pp.529-546. https://doi.org/10.1002/hipo.22709.

Persistent Link:

http://hdl.handle.net/11343/292382 